Review

\title{
Harnessing ionic mechanisms to achieve disease modification in neurodegenerative disorders
}

\author{
A Masi $^{\mathrm{a}, \mathrm{b}, *, 1}, \mathrm{R}_{\text {Narducci }}{ }^{\mathrm{c}, 1}, \mathrm{G}$ Mannaioni $^{\mathrm{a}, \mathrm{d}, 1}$ \\ ${ }^{a}$ Department of Neuroscience, Psychology, Drug Research and Child Health (NEUROFARBA), Section of Pharmacology and Toxicology, University of Florence, Florence, \\ Italy \\ ${ }^{\mathrm{b}}$ School of Pharmacy, University of Camerino, Camerino, Italy \\ ${ }^{\mathrm{c}}$ Italian Institute of Technology (IIT), Department of Neuroscience and Brain Technologies, Genova, Italy \\ ${ }^{\mathrm{d}}$ Toxicology Unit, Azienda Ospedaliero-Universitaria Careggi, Florence, Italy
}

\section{A R T I C L E I N F O}

Chemical compounds studied in this article: Anle 138b (PubChem CID: 44608289) Baclofen (PubChem CID: 2284) Chlorzoxazone (PubChem CID: 2733) Dantrolene (PubChem CID: 6914273) Diazoxide (PubChem CID: 3019) Flecainide (PubChem CID: 3356) Isradipine (PubChem CID: 3784) Lamotrigine (PubChem CID: 3878) Memantine (PubChem CID: 4054)

Riluzole (PubChem CID: 5070)

\section{Keywords:}

Neurodegenerative disorders

Neurodegeneration

Neuroprotection

Parkinson's disease

Alzheimer's disease

Amyotrophic lateral sclerosis

Spinocerebellar ataxia

Retinal degenerative disorders

Ion channels

Patch clamp

Mitochondria

Oxidative stress

\begin{abstract}
A B S T R A C T
Progressive neuronal death is the key pathogenic event leading to clinical symptoms in neurodegenerative disorders (NDDs). Neuroprotective treatments are virtually unavailable, partly because of the marked internal heterogeneity of the mechanisms underlying pathology. Targeted neuroprotection would require deep mechanistic knowledge across the entire aetiological spectrum of each NDD and the development of tailored treatments. Although ideal, this strategy appears challenging, as it would require a degree of characterization of both the disease and the patient that is currently unavailable. The alternate strategy is to search for commonalities across molecularly distinct NDD forms and exploit these for the development of drugs with broad-spectrum efficacy. In this view, mounting evidence points to ionic mechanisms (IMs) as targets with potential therapeutic efficacy across distinct NDD subtypes. The scope of this review is to present clinical and preclinical evidence supporting the link between disruption of IMs and neuronal death in specific NDDs and to critically revise past and ongoing attempts of harnessing IMs for the development of neuroprotective treatments.
\end{abstract}

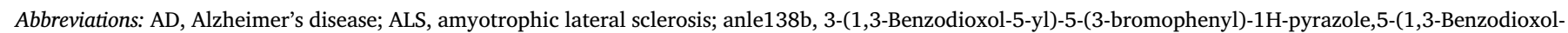

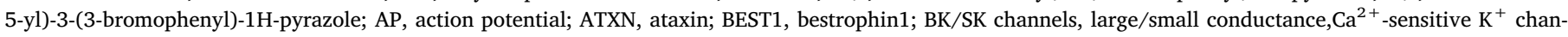

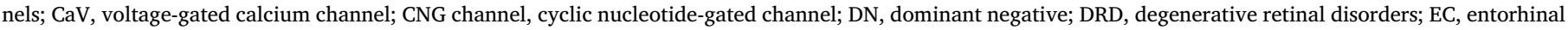

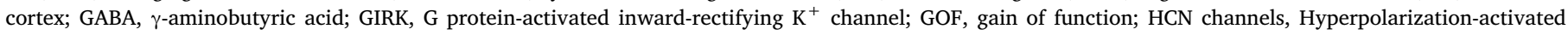

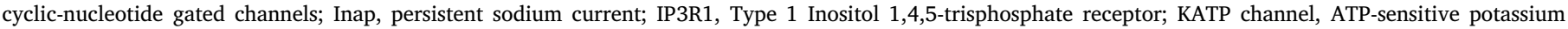

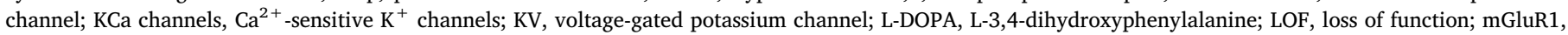

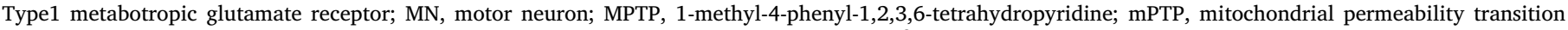

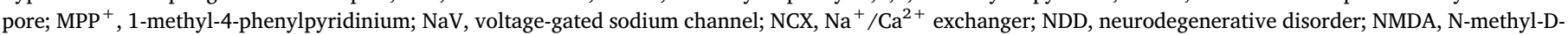

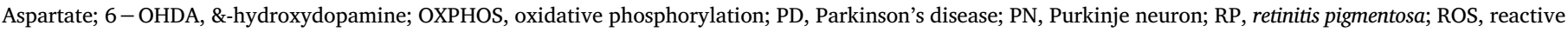

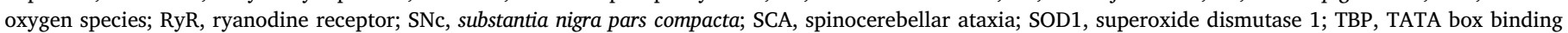
protein; TEA, tetraethylammonium; TRPC3, Transient receptor potential "canonical" type 3; VTA, ventral tegmental area

* Corresponding author.

E-mail address: alessio.masi@unifi.it (A. Masi).

1 equal contribution. 


\section{Introduction}

NDDs are typically defined as disorders of the nervous system in which slow but relentless cell death is the primary pathogenic event. Clinical manifestations typically mirror the pathophysiological alterations resulting from neuronal loss. NDDs are progressive and, since no cures are available, generally lethal. For some NDD classes, age is the main risk factor, hence the economic burden for the health systems of modern societies is constantly increasing due to rising life expectancy. While the optimal intervention would be neuroprotection, only treatments with partial symptomatic efficacy are currently available. When symptomatic treatments exist, as in the case of dopamine replacement therapy for Parkinson's Disease (PD), relief is transient and oftentimes associated to severe side effects. For other NDD classes, such as Alzheimer's disease (AD), even the management of symptoms is unsatisfactory. Overall, the massive effort made with both public and private investments in the quest for neuroprotective therapies has been largely frustrated by the disappointing outcomes of clinical trials. Nonetheless, thanks to progresses made by genetic studies and the widespread utilization of disease animal models, significant steps forward have been taken in the comprehension of the pathogenic pathways underlying NDDs. Besides confirming the high degree of aetiopathogenic diversity across different NDDs, which is hardly surprising, an unexpected level of internal heterogeneity in the pathogenic mechanisms underlying individual NDD classes has emerged [1-4], thus supporting the proposition that NDDs are mere clinical entities in which defining symptoms arise from diverse molecular pathways. For translational prospects, the mechanistic complexity of NDD pathogenesis implies that multiple targets should be identified for each NDD subtype, to design specific neuroprotective therapies. An alternate option is to exploit common disease pathways with established pathogenic relevance across NDD subtypes, or even NDD classes, to develop treatments with broad-spectrum efficacy. In the following paragraphs, we will present multiple lines of evidence suggesting that mechanisms controlling the activity of principal ions, such as $\mathrm{Na}^{+}, \mathrm{K}^{+}, \mathrm{Ca}^{2+}, \mathrm{Cl}^{-}$ (henceforth collectively referred to as ionic mechanisms, IMs) and thereby the electrical properties of the neuron, are in the right position to serve as targets endowed with such potential. IMs take part in neurodegenerative processes at multiple levels and in complex ways. In some diseases, the IMs underlying neuron-specific electrical properties may cause heightened sensitivity towards genetically-determined or environmental risk factors. In other cases, innate or acquired defects in IMs shaping the electrical profile of the neuron may drive disease progression. In either case, pathogenic steps driven by IMs are found at the crossroads of multiple pathways across molecularly distinct NDD subtypes, or even across distinct diseases. The present article aims at providing a non-systematic, critical revision of preclinical and clinical evidence supporting the existence of a causal link between IMs function/dysfunction and neuronal degeneration. To this aim, we will first concisely overview common terminal events causing neuronal death across diverse NDD classes. Afterwards, we will consider selected NDD classes where IMs have been involved in pathogenesis or used as pharmacological targets, in preclinical or clinical settings, in the attempt to achieve disease modification.

\section{Terminal cell death mechanisms activated by IMs-related pathogenic pathways in NDDs}

Neurons are excitable cells whose electrical properties are governed by the expression and activity of a large complement of IMs. IMs determine the polarity and magnitude of resting membrane potential, support the generation and propagation of the action potential (AP) and enable synaptic transmission. In the classical view, IMs are seen as downstream elements of the biological information flow, their function being controlled by transcription level, post-translational modifications, subcellular distribution pattern and physical interaction with ancillary subunits or membrane constituents. In physiological conditions, IMs function does not impinge on the overall health state of the neuron. When these are dysfunctional, however, normal electrical activity is disrupted and neurological disorders may occur. In some cases, the link between clinical manifestations and defective electrical properties is direct. In epilepsy, the prototypical ion channel-related disease (or "channelopathy"), mutations in specific classes of voltage-gated ion channels cause elevated spike probability at single neuron level and the occurrence of hypersynchronous activity [5]. Neurodegeneration may appear in advanced stages of the disease as a long-term consequence of exceeding glutamate release and N-methyl-D-aspartate (NMDA) receptor-mediated $\mathrm{Ca}^{2+}$ overload on postsynaptic neurons, a phenomenon known as "excitotoxicity". However, neuronal death is not the cause of pathophysiological alterations in epilepsy, but rather a consequence of these [6]. Therefore, effective management of symptoms prevents neuronal death [7]. In NDDs, in contrast, neuronal death is the key pathogenic event, that normally precedes or accompany symptomatology. In this class of neurological disorders, numerous alterations have been associated to neuronal death in a limited number of pathways, including energy metabolism, mitochondrial function/redox state, protein turnover. In this picture, IMs may drive disease in three manners. First, the normal neuronal complement of IMs may result in intrinsic vulnerability towards genetically-encoded or sporadic disease causes/risk factors. Hence, IMs add to other determinants, such as morphology, energy demand, constitutive ROS production, neurochemical and protein content, in shaping an innate, cell type-specific vulnerable phenotype. Second, the activation of disease pathways of diverse nature may disrupt physiological IMs operation. Acquired functional alteration may in turn engender a pathological electrical phenotype promoting cell death. Third, mutations in IMs-encoding genes may be the primary cause of neuropathology, cell death and neurological manifestations. Although uncommon, these "neurodegenerative channelopathies" are very instructive, as they reflect the strong relation of causality and sufficiency that may establish between ionic signalling and neuronal death.

Early evidence for the capability of dysfunctional IMs to trigger degenerative neuronal death comes from mechanistic studies in animal models. The weaver mutation in the mouse is a paradigmatic case of neurodegenerative channelopathy. The weaver neurological phenotype, characterized by ataxia and gait abnormalities, is caused by a spontaneous, single nucleotide substitution in the KCNJ6 gene, encoding the $\mathrm{G}$ protein-activated inward-rectifying $\mathrm{K}^{+}$channel (GIRK) 2 [143]. Because of the nucleotide switch, the channel turns into a nonselective, constitutively active cation conductance. Dopaminergic (DAergic) neurons of the substantia nigra pars compacta (SNc) in brain slices prepared from these mice show depolarized membrane potential, absence of spontaneous firing and increased membrane conductance [8]. In association to aberrant electrophysiological phenotype, homozygous weaver mice develop distinctive neuropathology including SNc-specific DAergic degeneration [143] between postnatal days 7 and 21. The remarkable neuropathological phenotype caused by the weaver mutation is a milestone for the study of the interplay between IMs and neuronal survival, as it provides hard evidence that a single-nucleotide, gain-offunction mutation in a membrane-resident ion channel, besides altering single-cell electrophysiological properties, can put at risk the very survival of the neuron. Finally, the weaver mouse highlights the concept of differential vulnerability. Expression of GIRK2 channels is widespread in the brain, yet only a few populations are affected by the mutation, indicating that some populations are more susceptible to the detrimental effects of changes in their electrical phenotype [8].

A detailed description of the chemical and molecular events triggering death pathways at single cell level is beyond the scope and the possibilities of this review. However, for the sake of completeness, it is necessary to mention the cellular mechanisms which play a critical role in transducing ionic dyshomeostasis or altered electrical properties in a death signal. Fig. 1 shows an overview of the main death pathways 

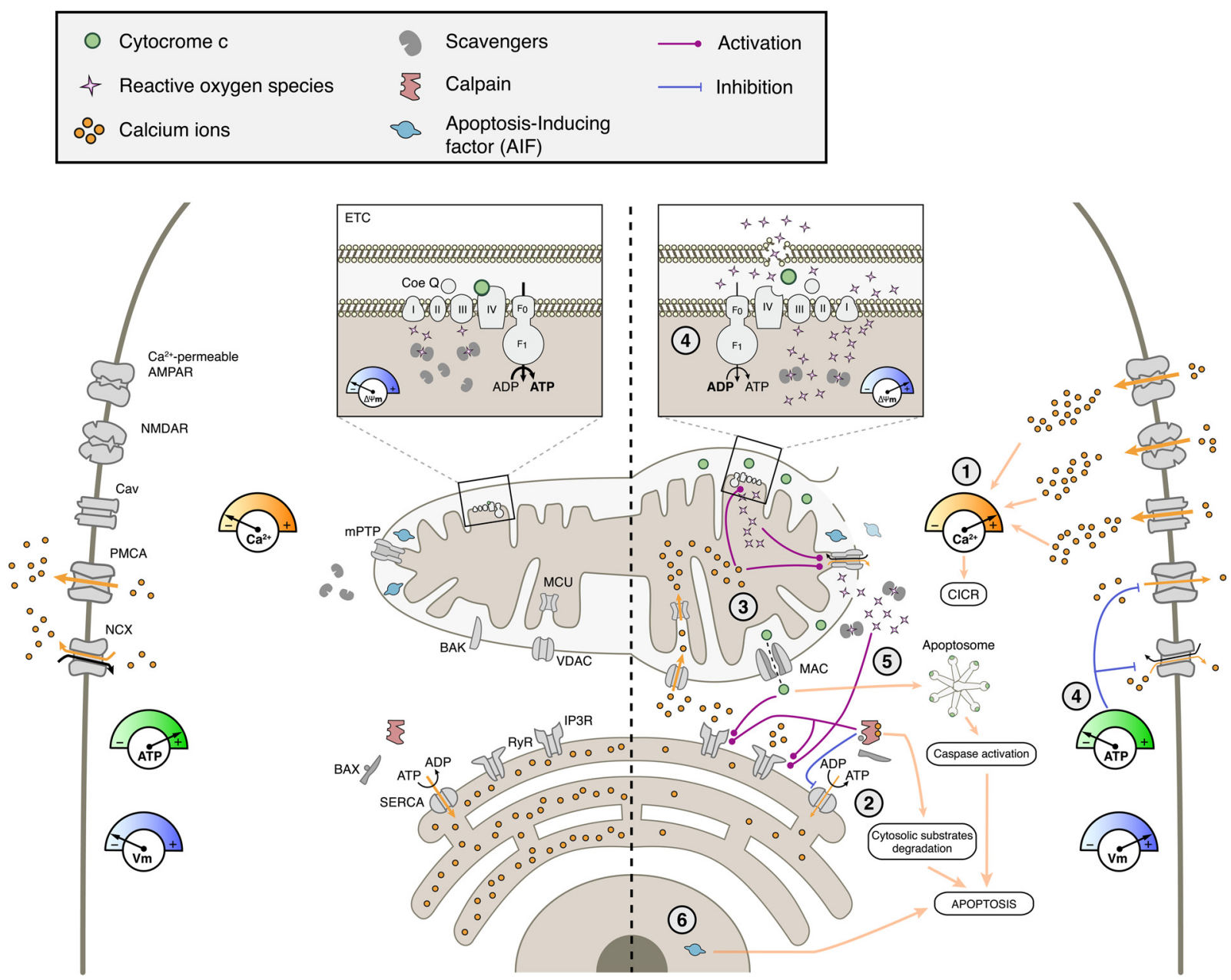

NORMAL

DISEASE

Fig. 1. Common cell death mechanisms triggered by IMs-related pathways underlying NDDs.

Left, healthy neuron: intracellular ATP concentration and synthesis is normal and sufficient for the maintenance of all the ionic gradients sustained by the activity of primary and secondary active transporters. Resting membrane potential $\left(\mathrm{V}_{\mathrm{M}}\right)$ is normal $(\sim 60 \mathrm{mV})$ and cytosolic $\mathrm{Ca}^{2+}$ concentration is kept in the submicromolar range by the sustained activity of extracellular (PMCA and NCX) and ER membrane transporters/pumps (SERCA). Inset: scheme of the electron transport chain (ETC). Cytochrome $\mathrm{c}$ is loosely associated to the ETC and transfers electrons from complex III to complex IV. ATP production is optimal and the reactive oxygen species (ROS) released by this process are quenched by mitochondrial and cytosolic scavengers. Mitochondrial membrane potential $(\Delta \Psi \mathrm{m})$ is highly polarized $(-150 \mathrm{mV})$. Because of the low cytosolic $\mathrm{Ca}^{2+}$ concentration, the activity of voltage-dependent anion channel (VDAC) and the mitochondrial calcium uniporter (MCU) is low, resulting in minimal concentration of $\mathrm{Ca}^{2+}$ inside the mitochondria. In presence of low mitochondrial $\mathrm{Ca}^{2+}$ and ROS levels the mitochondrial permeability transition pore (mPTP) is mostly in the closed state. Major pro-apoptotic proteins, such as cytochrome c and apoptosis-inducing factor (AIF) are either confined inside the mitochondria or in an inactive state in the cytosol (BAK, BAX and calpain).

Right, pathological context (numeration is not indicative of chronological order). (1) Cytosolic $\mathrm{Ca}^{2+}$ concentration rises following the activation of NMDAR, Ca $\mathrm{V}$ and $\mathrm{Ca}^{2+}$-permeable AMPAR. (2) Increased cytosolic $\mathrm{Ca}^{2+}$ concentration causes calcium-induced-calcium-release (CICR), leading to $\mathrm{Ca}^{2+}$ outflow from the ER lumen through RyR and IP3R [11]. (3) $\mathrm{Ca}^{2+}$ influx inside the mitochondrial matrix through VDAC and MCU causes an increase in ROS production followed by cytochrome c oxidation [12]. Elevated ROS and $\mathrm{Ca}^{2+}$ concentrations causes MPTP opening, additional release of $\mathrm{Ca}^{2+}$ in the cytosol and massive entry of water and solutes into the mitochondria, which eventually lead to organelle swelling and rupture of the outer membrane [12]. (4) Cytochrome $c$ is released in the intermembrane space and ATP production diminishes [13]. The decrease in ETC efficiency leads to general energy shortage [14], slowing the activity of transporters and thus further increasing intracellular $\mathrm{Ca}^{2+}$ concentration. (5) $\mathrm{Ca}^{2+}$-activated calpain cleaves cytosolic BAX, that assembles with BAK and mitochondrial proteins to form the mitochondrial apoptosis-induced channel (MAC) [15,16]. This complex boosts RyR and $\mathrm{IP}_{3} \mathrm{R}$ activity [17] and promotes the degradation of cytosolic substrates [18]. Elevated ROS production overwhelms the quenching activity exerted by scavengers causing lipid peroxidation and additional boosting of RyR activity. (6) Apoptosis is also driven by two additional processes consisting in the formation of the apoptosome, a protein complex including cytochrome c leaked out of mitochondria through MAC $[15,16]$ and the translocation of AIF into the nucleus, responsible for chromatin condensation and DNA fragmentation [19].

leading to cell death when IMs are disrupted in NDDs. Details on these pathways, along with references to excellent reviews addressing this topic, can be found in the figure legend.

The main link between IMs and neuronal fate is the interplay with energy metabolism and the redox state of the cell. The maintenance of electrochemical gradients across biological membranes, required for normal neuronal operation, comes to high metabolic cost. While representing $2 \%$ of the total body weight, the brain accounts for $20 \%$ of all the oxygen and energy consumed by the body $[9,10]$. Intense mitochondrial activity is necessary to produce the ATP required for active ionic transport mechanisms. Massive ATP amounts are constantly consumed by the $\mathrm{Na}^{+} / \mathrm{K}^{+}$and $\mathrm{Ca}^{2+}$ ATPases to sustain the physiological resting membrane potential and the steep $\mathrm{Ca}^{2+}$ gradient across the plasma membrane and the endoplasmic reticulum (ER) membrane. 
Deviations from physiological ionic homeostasis may result from a number of alterations in any of the IMs mediating active and passive ionic fluxes. In spite of the great heterogeneity of alterations, the terminal events ultimately determining neuronal demise are essentially two: pathological $\mathrm{Ca}^{2+}$ signalling and oxidative stress.

$\mathrm{Ca}^{2+}$-mediated processes are involved in nearly all physiological activities of the healthy neuron. Physiological $\mathrm{Ca}^{2+}$ transients are generally spatially-confined and short-lasting. This is permitted by the action of ATP-dependent $\mathrm{Ca}^{2+}$-clearing mechanisms. $\mathrm{Ca}^{2+}$ dyshomeostasis is a major cell death trigger, not only in neuronal cells, and prolonged deviations from physiological intracellular $\mathrm{Ca}^{2+}$ concentration triggers a host of cellular pathways eventually causing cell death, including the calpain cascade, resulting in degradation of cytoskeletal proteins and apoptotic death. Elevated cytosolic $\mathrm{Ca}^{2+}$ activates feedforward processes such as a calcium-induced calcium release (CICR), mediated by ER-resident $\mathrm{Ca}^{2+}$ conductances such as the ryanodine receptor (RyR) and the Inositol 1,4,5-trisphosphate receptor $\left(\mathrm{IP}_{3} \mathrm{R}\right)$.

In normal conditions, mitochondria are low-affinity, high-capacity $\mathrm{Ca}^{2+}$ reservoirs. Moderate increase in $\mathrm{Ca}^{2+}$ levels in the matrix is perceived as an elevated ATP demand. Therefore, Krebs cycle and oxidative phosphorylation (OXPHOS) are stimulated. The latter is the primary source of reactive oxygen species (ROS) in the cell. ROS are very reactive, yet short lived, molecules which are normally neutralized by scavenging enzymes, such as superoxide dismutase (SOD) and catalase. When ROS production, due to high ATP demand, exceeds the cellular scavenging capacity, oxidative stress may occur. Elevated cytosolic $\mathrm{Ca}^{2+}$ may result from a variety of electrophysiological aberrations, including hyperexcitability, pathological activation of plasma membrane $\mathrm{Ca}_{\mathrm{V}}$ channels or $\mathrm{Ca}^{2+}$-permeable glutamate receptors, such as the NMDA receptor.

\section{Parkinson's disease}

Parkinson's Disease (PD) is the second most common NDD in developed countries, with a prevalence of about $2 \%$ in the population over 65 years of age [20]. Typical motor symptoms, such as resting tremor, rigidity and bradykinesia, result from the massive degeneration of dopamine (DA) neurons of the substantia nigra pars compacta (SNc) and ensuing reduction of DA levels in dorsal striatum, a subcortical structure involved in the control of voluntary movement. The vast majority ( $\sim 90 \%$ ) of PD cases have sporadic nature, the remaining cases being caused by fifteen disease-causing monogenic mutations denominated PARK 1-15 [21,22]. In addition to genetic causes, 26 genetic risk factors have been identified by genome-wide association studies [1,22], suggesting the existence of great heterogeneity in the mechanisms leading to clinical PD. The incomplete understanding of such complex pathogenic scenario has been suggested as the main cause for the failure of disease-modifying drugs in clinical trials [23]. In spite of the etiopathogenic diversity, there is evidence that multiple disease-causing factors converge to determine a relatively homogeneous pathological scenario in PD, which includes mitochondrial deficit, oxidative stress and impaired protein turnover [24]. In the past 15 years, a number of studies have focused on IMs in search for determinants of the vulnerable DAergic phenotype [25,26]. Midbrain DAergic neurons are characterized by unstable membrane potential and intrinsic AP generation [27]. Spontaneous firing activity is sustained by the coordinated action of a large complement of voltage-gated ion channels expressed in the somatodendritic compartment [28], which requires continuous restoration of ionic gradients across the plasma membrane by active transport systems and intense ATP consumption [10]. ATP levels must be constantly restored by oxidative OXPHOS in mitochondria. Mitochondrial OXPHOS is the main source of reactive oxygen species (ROS) in the cell, and when ROS production exceeds the scavenging capacity of redox systems, oxidative stress may occur. Oxidative stress causes non-specific chemical damage to cellular constituents, such as membrane lipids, proteins and nucleic acids, with lethal consequences for the cell [29]. Mitochondrial function, ROS metabolism and IMs are interconnected and exert reciprocal influence. ATP-sensitive $\left(\mathrm{K}_{\mathrm{ATP}}\right)$ potassium channels are a striking example of a plasma membrane IM under metabolic control [30]. $\mathrm{K}_{\mathrm{ATP}}$ channels are negatively regulated by ATP levels, thus they open in presence of low intracellular ATP causing membrane hyperpolarization and silencing of the electrical activity. $\mathrm{K}_{\mathrm{ATP}}$ channels are widely expressed in nerve cells, where they are thought to serve as metabolic sensors braking energy-demanding electrical activity in case of ATP supply shortage [31,32]. In the early 2000s, Roeper and co-workers demonstrated that $\mathrm{K}_{\mathrm{ATP}}$ channels in SNc DAergic neurons are particularly sensitive to the metabolic failure induced by MPTP or rotenone, two chemically distinct complex I blockers used to generate animal models of environmental PD. Both ATP depletion and perfusion of complex I blockers cause activation of $\mathrm{K}_{\mathrm{ATP}}$ channels, reduction of firing rate and neuronal silencing during brain slice recordings. The additional finding that genetic inactivation of $\mathrm{K}_{\mathrm{ATP}}$ channels reduces nigrostriatal degeneration in the MPTP-intoxicated and weaver mouse models suggests that $\mathrm{K}_{\mathrm{ATP}}$ channels activation is a mechanism of broad relevance in DAergic degeneration [33]. To explain how $\mathrm{K}_{\mathrm{ATP}}$-dependent electrical silencing may cause selective nigrostriatal DAergic degeneration, the authors have proposed a neurophysiological version of the "use it or lose it" evolutionary theory. According to this hypothesis, individual neurons experiencing persistent reduction or complete silencing of their electrical activity, eventually undergo apoptotic cell death [34]. The experiments linking $\mathrm{K}_{\mathrm{ATP}}$ engagement and Parkinson-like neurodegeneration attracted great interest in the following years. Mercuri and co-workers demonstrated that $\mathrm{K}_{\mathrm{ATP}}$ in SNc DAergic neurons are gated by the mitochondrial toxin rotenone [35] and inhibited by memantine, a non-competitive glutamate NMDA receptor antagonist which showed neuroprotective efficacy in animal models [36]. A more recent study reported the neuroprotective effect of $\mathrm{K}_{\mathrm{ATP}}^{+}$blockade in PD animal models [37]. In this work, the $\mathrm{K}_{\mathrm{ATP}}$ blocker and antidiabetic glibenclamide was able to protect from 6-OHDA-induced nigrostriatal lesion. In spite of the compelling experimental evidence linking $\mathrm{K}_{\mathrm{ATP}}^{+}$channels activation to nigrostriatal degeneration in preclinical models, the lack of disease specificity and the critical involvement in the regulation of blood glucose level may have hindered further exploitation of this target. As of today, modulators of $\mathrm{K}_{\mathrm{ATP}}$ channels have never been tested in clinical trials.

The recapitulation of molecular pathways causing selective vulnerability of SNc DAergic neurons triggers electrophysiological abnormalities which have been proposed to determine the vulnerable neuronal phenotype in PD animal models. These abnormalities often involve the disruption of cell-autonomous mechanisms controlling intrinsic generation of rhythm. Electrophysiological recordings from single neurons in vivo demonstrated that pharmacological inhibition of the Ubiquitin-proteasome system (UPS) causes acceleration of the firing frequency in surviving SNc but not VTA DAergic neurons. Post hoc histological examination showed SNc-limited loss of DAergic neurons, thus establishing a strong, yet associative, link between electrical alterations and neurodegeneration [38]. Selective increase of firing frequencies in SNc DAergic neurons was also reported in transgenic mice expressing a mutant form of the human $\alpha$-synuclein (A53T-SNCA) before symptoms onset. At molecular level, the alteration in firing rate was partly mediated by a functional impairment of A-type $\mathrm{K}_{\mathrm{V}} 4.3$ potassium channels. Oxidative dysfunction of the channel was proposed as the mechanism linking mutant $\alpha$-synuclein and functional alteration, as this was prevented by glutathione perfusion [39]. Although the demonstration of a mechanistic link between IMs dysfunction and neurodegeneration is lacking, these reports indicate that distinct PD-relevant pathogenic pathways selectively disturb the normal electrical activity in vulnerable neurons. Moreover, at least in the latter study, electrophysiological alterations induced by the mutation are manifest at early stage of disease progression, suggesting that they may represent potential targets for disease modification.

As mentioned, the functional coupling between energy metabolism 
and IMs is bidirectional, and the activity of certain membrane conductances may affect the energy demand of the neuron. Elevated metabolic activity required to meet the energy request may in turn act as a susceptibility factor towards genetic or sporadic risk factors and the IMs imposing such metabolic burden on the neuron represent ideal targets for protective medications with therapeutic relevance across the entire aetiological spectrum of PD. By using electrophysiology, pharmacology and calcium imaging in brain slices, DJ Surmeier and co-workers showed that SNc DAergic neurons in rodent brain slices display dendritic $\mathrm{Ca}^{2+}$ oscillations, which are phase-locked to, but not required for intrinsic firing activity [40]. The authors showed that dendritic $\mathrm{Ca}^{2+}$ oscillations are mediated by $\mathrm{Ca}_{\mathrm{v}} 1.3$, and that constant removal of $\mathrm{Ca}^{2+}$ from the cytosol poses a significant metabolic burden for the neuron [41]. To keep up with ATP-demanding $\mathrm{Ca}^{2+}$ pumps, mitochondria need to maintain relatively high rates of ATP production, which result in high levels of ROS generation. Furthermore, it was proved that SNc DAergic neurons have higher OXPHOS basal activity and associated ROS production compared to nearby VTA DAergic neurons and that isradipine, $\mathrm{a} \mathrm{Ca}_{\mathrm{V}}$ 1.2-1.3 blocker, stops dendritic $\mathrm{Ca}^{2+}$ oscillations and lowers oxidative stress in physiological conditions [42] as well as in presence of PD-relevant mutations [41,43]. Furthermore, isradipine was shown to afford protection from nigrostriatal neurodegneration in a 6-OHDA mouse model [44]. Isradipine is a dihydropiridine with negative allosteric modulation activity and equal affinity for $\mathrm{Ca}_{\mathrm{V}} 1.2$ and 1.3, already approved by FDA and other regulatory bodies for the treatment of high blood pressure (DynaCirc ${ }^{\mathrm{TM}}$ ). Building on the promising preclinical studies described above, isradipine is now being tested in a phase III clinical trial named STEADY-PD III (ID: NCT02168842). STEADY-PD III is a double-blind, randomized, placebocontrolled study, started in 2014 and to be completed in March 2019. The study, involving 336 participants with early stage clinical PD, not receiving or requiring symptomatic therapy at start date, aims at testing the neuroprotective efficacy of isradipine over the 36-month trial period, as measured with the total Unified Parkinson Disease Rating Scale (UPDRS) score [45]. So far, this is the only clinical trial based on the modulation of an IM as a neuroprotective approach in PD. Of note, the rationale at the basis of the study is supported by retrospective population studies associating the use of centrally-acting $\mathrm{Ca}^{2+}$-blockers to a significant $(\sim 30 \%)$ reduction in the risk of developing PD $[46,47]$.

More recently, another family of voltage-gated ion channels has been proposed as an intrinsic determinant of the vulnerable phenotype of SNc DAergic neurons. With brain slice patch clamp recordings, the authors of the present manuscript demonstrated that the PD-causing toxin $\mathrm{MPP}^{+}$inhibits Hyperpolarization-activated cyclic nucleotidegated (HCN) channels in SNc DAergic neurons [48]. HCN channels conduct a hyperpolarization-activated, inward cationic current which promotes pace-making and controls synaptic excitability [48-50]. In SNc Daergic neurons, HCN current is carried by the HCN2 and 4 isoforms, which distinguish themselves from isoforms 1 and 3 for higher cAMP sensitivity [51]. HCN current inhibition causes rapid reduction of autonomous spiking and marked increase in synaptic excitability [48]. Furthermore, the electrophysiological effects exerted by pharmacological inhibition of HCN current, as well as the ensuing somatic $\mathrm{Ca}^{2+}$ inflow, is larger in vulnerable $\mathrm{SNc}$ as compared to resistant VTA DAergic neurons [52]. Finally, it was shown that chronic inhibition of HCN current attained with local administration of two distinct HCN blockers, causes DAergic neuronal death in the SNc, but not in the VTA, of normal adult rats [53]. Based on their results, the authors speculate that HCN current may undergo loss of function (LOF) during the early phases of disease progression, possibly as a consequence of metabolic fatigue, and drive $\mathrm{Ca}^{2+}$-mediated toxicity, thus representing an SNcspecific pathogenic pathway. Because no association between HCN mutations and PD have been discovered so far, it remains to be determined whether HCN LOF participates in the pathogenic cascade of clinical PD and how genetic or sporadic PD-triggers induce HCN LOF. In this respect, it was demonstrated the HCN current is negatively modulated by acute inhibition of mitochondrial ATP production, an effect resembling that induced by low intracellular cAMP [53]. It is plausible that metabolic stress and reduced ATP production result in reduced cAMP synthesis in preclinical stages of PD. In agreement with this proposition, HCN LOF was reported in SNc DAergic neurons of early stage Mitopark mice, an animal model in which a Cre-dependent, DAergic-restricted mitochondrial mutation drives late-onset, slow-progressing nigrostriatal degeneration and, eventually, PD motor symptoms $[54,55]$. For translational prospects, HCN channels can be envisioned as amenable pharmacological targets. However, experimental data point to inverse causal relation between HCN current and PD pathogenesis. In other words, according the HCN hypothesis, neuroprotection would be afforded in PD by functional enhancers. The design of ion channels' enhancers is a highly challenging endeavour for medicinal chemistry and specific HCN enhancers are not yet available [56]. No ongoing clinical studies are directly testing the neuroprotective efficacy of HCN functional rescue. However, there is preclinical and clinical evidence consistent with a contribution of HCN LOF in PD-related neurodegeneration. The anticonvulsant drug lamotrigine, which also shows HCN-enhancing action in DAergic neurons [57] protects from MPTP-induced degeneration [58]. In the latter report, two different anticonvulsants devoid of HCN-boosting activity such as topiramate and valproate failed to afford neuroprotection, suggesting that the neuroprotective effect exerted by lamotrigine may be HCN-mediated. Recently, a large observational clinical study showed that subjects taking salbutamol for the treatment of asthma have reduced risk of developing PD [59]. Salbutamol is a brain-penetrant $\beta_{2}$ adrenergic receptor agonist stimulating intracellular cAMP synthesis. Although it was not tested in these studies, it is tempting to speculate that HCN upregulation contributes to the neuroprotective effect of these drugs. Altogether, preclinical and clinical data prompt to investigate in more detail the potential of $\mathrm{HCN}$ channels as targets for neuroprotection in PD.

The hypothesis of a contribution of excitotoxicity to PD pathogenesis has provided the rationale for preclinical and clinical studies in the past. Memantine has been extensively studied in preclinical models and in clinical trials as a neuroprotective agent in PD and other NDDs because of its presumed anti-excitotoxic action. Clinical trials have provided modest results in the management of PD-related cognitive decline [60] and motor symptoms [61] while there is no evidence in the literature of a clinical study testing memantine as a neuroprotectant in prodromic or early-stage PD patients. Based on the same rationale, the voltage-gated $\mathrm{Na}^{+}$channel blocker riluzole is proposed to counteract the excitoxic component in NDDs and thus currently used in the therapy of ALS. Riluzole has been tested for many years as a neuroprotectant also in preclinical models of PD, with modest results [62]. One single study has tested riluzole in early-stage PD patients in 2002 failing to show any beneficial effect on clinical manifestations, although the short duration ( $\leq 1$ year) and the very small sample (20 patients) may have weakened the power of this study [63]. Fig. 2 (top) illustrates major contributions of IMs to PD pathogenesis, according to the current understanding.

\section{Alzheimer's disease}

Alzheimer's disease (AD) is the primary cause of dementia in western societies. At onset, disease symptoms may be subtle and go unnoticed, but the inevitable progression leads to severe cognitive impairment and, eventually, death. The main neuropathological hallmarks are extracellular deposition of $\beta$-amyloid (A $\beta$ ) plaques and intracellular accumulation of neurofibrillary tangles containing hyperphosphorylated tau protein [64-66]. The aetiology of the disease is essentially unknown and the vast majority of cases are sporadic. Some hints on the molecular aspects of the disease come from the study of genes mutated in familial forms. Patients with familial AD, characterized by early age of onset ( $<50$ years), carry mutations in genes 
NORMAL

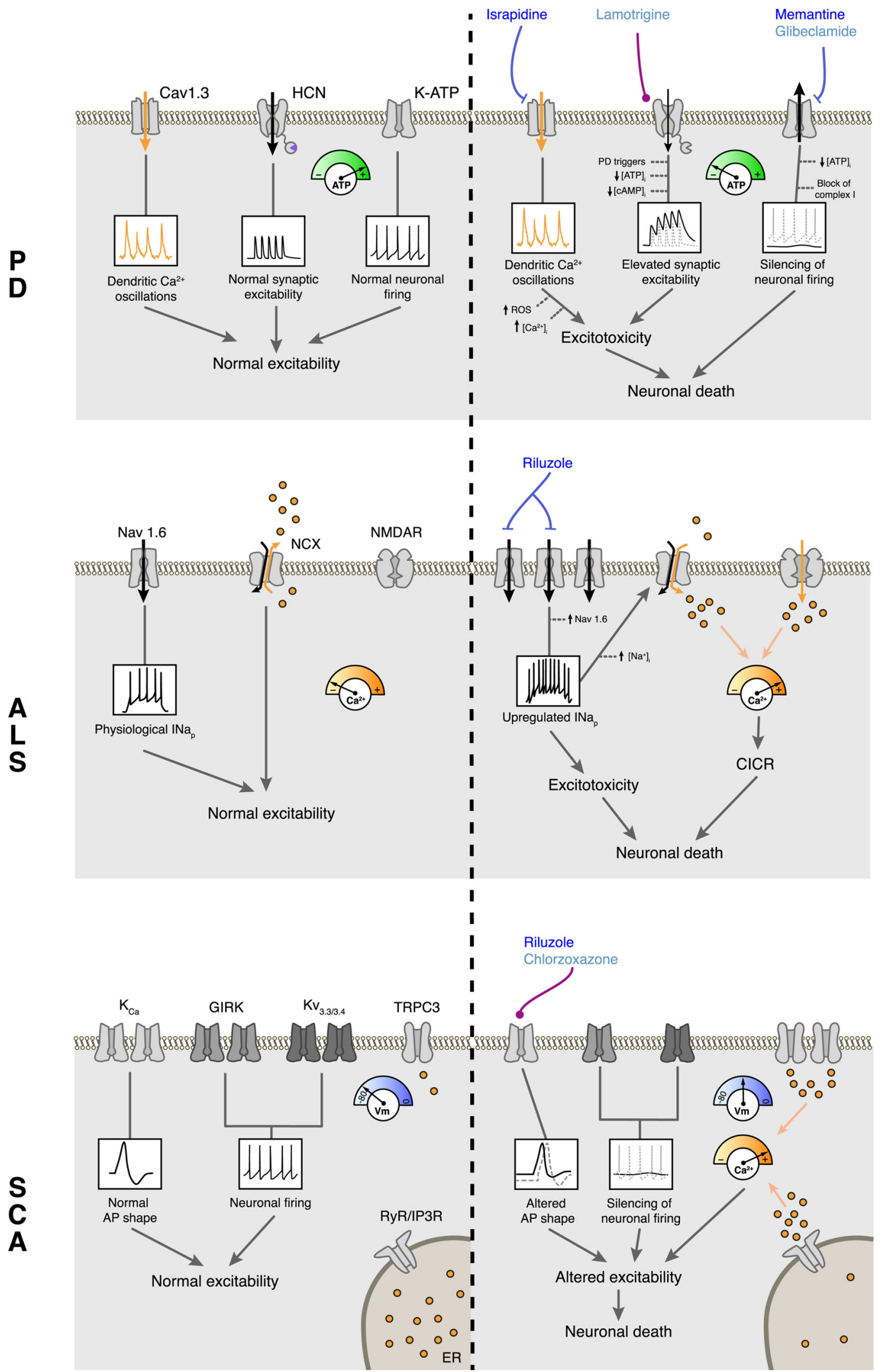

Fig. 2. Role of IMs and altered electrical activity in the pathogenic processes underlying selected NDDs.

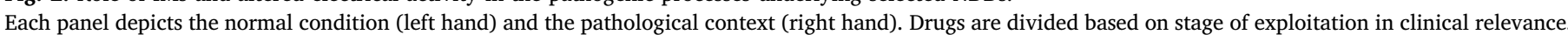
In dark blue, those employed as disease modifiers, in light blue those still in a preclinical stage. 
encoding amyloid precursor protein (APP), presenilin 1 and presenilin 2 , all involved in the formation of $A \beta$ oligomers. Studies on these pathways have led to the hypothesis that $A \beta$ self-aggregation and plaque formation is the key pathogenic process in $\mathrm{AD}$, although the details of the link between neuropathological alterations and neuronal cell death are incompletely understood. While there is increasing evidence pointing to remarkable genetic and molecular heterogeneity in $\mathrm{AD}[3,67]$, calcium dysregulation has emerged as a common denominator driving neuronal death [68-70]. A great deal of interest was raised by early studies showing that $A \beta$ oligomers were able to directly perturb $\mathrm{Ca}^{2+}$ homeostasis in cellular systems. Patch clamp recordings obtained from excised membrane patches incubated in the presence of $A \beta$ oligomers showed that these can assemble to form $\mathrm{Ca}^{2+}$-permeable pores in the plasma membrane [71-73]. It has been recently demonstrated that the $\mathrm{A} \beta 1-42$ peptide, but not the related 1-40 peptide, is responsible for the formation of membrane pores [74].

In addition to the remarkable example of $A \beta$ oligomers, in which the disease determinant acts as an aberrant IM itself, IMs may promote $\mathrm{AD}$ pathogenesis subsequently to the activation of $\mathrm{AD}$-related pathways. Indeed, numerous reports indicate that $\mathrm{A} \beta$ oligomers may affect a number of IMs in the cell membrane and thereby drive neuronal toxicity. In the cholinergic septal cell line SN56, A $\beta$ peptides induce activation of Tetraethylammonium (TEA)-sensitive outward $\mathrm{K}^{+}$currents. Pharmacological blockade of $\mathrm{K}^{+}$currents prevents $\mathrm{A} \beta$-induced toxicity [75]. In cultured hippocampal neurons, incubation with a synthetic $A \beta$ peptide causes a reversible voltage-dependent increase in membrane resistance, resulting from the inhibition of a fast-inactivating $\mathrm{K}_{\mathrm{V}}$ channel [76]. In the same experimental model, exposure to A $\beta$ 1-40 or A $25-35$ causes rapid and selective reduction in $\mathrm{Na}^{+} / \mathrm{K}^{+}$ATPase activity leading to membrane depolarization, disruption of $\mathrm{Ca}^{2+}$ homeostasis and cellular degeneration [77]. Additional pathogenic interactions between $\mathrm{AD}$-related mutations and IMs have emerged in more recent years, mainly from studies employing the 3XTgAD mouse model, a triple transgenic line carrying mutations causing autosomal dominant forms of clinical Alzheimer's and Frontotemporal Dementia [78]. In dissociated neurons obtained from 3XTgAD mice, the $\mathrm{K}_{\mathrm{ATP}}$ channel opener diazoxide is able to revert pathological changes in excitability, $\mathrm{Ca}^{2+}$ homeostasis and bioenergetics, while chronic administration of the compound in vivo reduces cognitive decline and ameliorates neuropathology in the cortex and hippocampus [79]. Endogenous A $\beta$ 1-43 peptide expressed in these mice was found to block large conductance, $\mathrm{Ca}^{2+}$-sensitive $\mathrm{K}^{+}(\mathrm{BK})$ channels and enhance $\mathrm{Ca}_{\mathrm{V}}$-mediated $\mathrm{Ca}^{2+}$ inflow in neocortical neurons [80].

Recently, promising results were reported on the neuroprotective action of Anle138b in the APPPS1 $\triangle \mathrm{E} 9$ mouse model of AD [81]. Anle138b is a small molecule able to ameliorate amyloid plaque pathology, LTP and spatial reference memory, with a mechanism involving inhibition of $\mathrm{Ca}^{2+}$ inflow through $\mathrm{A} \beta \mathrm{1}$ 1-42-formed pores. In addition to the restoration of physiological hippocampal operation and cognitive skills, a complete rescue of wild type-like gene expression profile was observed in treated animals. Importantly, the compound is orally available, shows good blood brain barrier penetration and no toxicity at therapeutic doses. Anle $138 \mathrm{~b}$ is a promising neuroprotectant also in other NDDs associated to toxic protein deposition. Indeed, the compound showed capability to inhibit oligomer accumulation, neuronal degeneration, and disease progression in vivo in three PD models [82] and has recently been tested with success in an animal model of Multiple System Atrophy [83].

$\mathrm{ER} \mathrm{Ca}^{2+}$ pool undergoes severe dysregulation in AD mouse models, including the 3XTgAD model. The aberrantly increased $\mathrm{ER} \mathrm{Ca}^{2+}$ signals are associated to AD-relevant mutations carried by the model and mediated by RyR overexpression, suggestive of a specific pathogenic pathway rather than a consequence of normal neuronal aging [84]. In a follow-up study, it was reported the RyR blocker dantrolene is able to normalize, in vitro, aberrant $\mathrm{Ca}^{2+}$ handling in $\mathrm{AD}$ mice [85]. A very recent report has shown that $\mathrm{HCN} 1$ channels undergo perisomatic ER sequestration in 3XTgAD mice. Therefore, HCN1 channels are mislocalized in hippocampal CA1 pyramidal neurons, and normal soma-todendrite expression gradient as well as dendritic integrative properties are disrupted. Administration of dantrolene or cyclopiazonic acid (a blocker of $\mathrm{ER} \mathrm{Ca}^{2+}$ pump) restores expression levels of HCN1 channels at cell surface and normalizes neuronal electrical properties in vitro. No explanation is provided as to the possible link between the reported alteration in HCN1 channels' trafficking and neuronal degeneration [86].

At present, the exploitation of IMs for the design of neuroprotective medications has not reached the stage of clinical studies in AD. AD pharmacotherapy is still based on the modest symptomatic efficacy showed by potentiation of cholinergic transmission achieved with cholinesterase inhibitors donepezil, rivastigmine and galantamine. Memantine is also used in AD therapy [87]. As a low-affinity antagonist of extrasynaptic NMDA receptors, the main mediators of the excitotoxic component in neuronal degeneration, memantine was suggested to have neuroprotective properties [88]. While several clinical studies have provided evidence for some pro-cognitive symptomatic efficacy of memantine, the presumed neuroprotective action of memantine has never been clearly established and remains, at present, largely hypothetical [87].

\section{Amyotrophic lateral sclerosis}

Amyotrophic lateral sclerosis (ALS) is caused by the degeneration of neurons controlling skeletal muscles, or motor neurons (MNs). Both cortical and spinal MNs, often referred to as "upper" and "lower" MNs respectively, are affected in the disease. Clinical manifestations include, at onset, muscle stiffness, twitching, and weakness. Later on, as a result of progressive neurodegeneration, muscles undergo atrophy, thus leading to the inability to speak, swallow and, in final stages, breath [89]. The causes of ALS are still largely unknown in sporadic forms, which account for $90-95 \%$ of cases, while some important mechanistic insight has emerged from the study of monogenic ALS forms. Several mutations in the superoxide dismutase 1 (SOD1), a key enzyme in the metabolism of reactive oxygen species, have been discovered in association with ALS [90]. Mice expressing the human SOD1 protein containing the G93A mutation display degeneration of motor neurons leading to paralysis and death at five months of age [91]. Notably, deletion of endogenous SOD does not lead to the development of ALS neuropathology and motor symptoms in mice [92], suggesting that neuronal toxicity associated to SOD mutations is independent from dismutase activity [93].

In the current view, ALS pathophysiology includes glutamate excitoxicity, oxidative stress, mutant SOD1 enzymes, mitochondrial dysfunction and disruption of axonal transport processes [94]. Recent studies have described dysfunction or aberrant subcellular localization of wild type SOD1 in sporadic ALS, providing evidence that the importance of this enzyme in ALS pathophysiology is not restricted to genetic forms [90]. As downstream events triggered by ALS causes, axonal hyperexcitability and associated glutamate receptor-mediated excitotoxicity have emerged as major processes driving neurotoxicity. Of note, cortical hyperexcitability, a neurological index of early ALS, has been reported in carriers of SOD1 mutations before the onset of clinical symptoms, suggesting a critical contribution of aberrant electrical activity as a driver of ALS progression [89]. According to the "dying forward" hypothesis, hyperactivity of cortical MNs induces NMDA receptor-mediated excitotoxicity on spinal postsynaptic MNs [95]. The SOD1 mouse model shows hyperexcitability and degeneration of MNs, thus pointing to the presence of a mechanistic link between ROS metabolism, alterations in IMs and neuronal degeneration. Abnormalities in $\mathrm{Na}^{+}$and $\mathrm{K}^{+}$conductances contribute to the development of membrane hyperexcitability in ALS, thereby leading to disease hallmarks such as muscle cramps and fasciculations, in addition to promoting a neurodegenerative cascade via a number of $\mathrm{Ca}^{2+}$. 
mediated processes [96]. Among the $\mathrm{Na}^{+}$conductances involved in ALS-related axonal hyperexcitability, the persistent $\mathrm{Na}^{+}$current $\left(\mathrm{INa}_{\mathrm{p}}\right)$ seems to play a pivotal role. $\mathrm{INa}_{\mathrm{p}}$ is mediated by $\mathrm{Na}_{\mathrm{V}} 1.6$ channels. Compared to the other members of the $\mathrm{Na}_{\mathrm{V}}$ family, $\mathrm{Na}_{\mathrm{V}} 1.6$ shows very slow and incomplete inactivation. $\mathrm{INa}_{\mathrm{p}}$ is functionally upregulated in ALS animal models $[97,98]$. Furthermore, studies in both sporadic and familial ALS patients reported alterations in axonal excitability consistent with increased $\mathrm{INa}_{\mathrm{p}}$ [99]. Upregulation of $\mathrm{INa}_{\mathrm{p}}$ perturbs the ionic homeostasis by increasing intracellular $\mathrm{Na}^{+}$concentrations. In turn, this results in reverse operation of the $\mathrm{Na}^{+} / \mathrm{Ca}^{2+}$ exchanger (NCX). In physiological conditions, NCX exchanges intracellular $\mathrm{Ca}^{2+}$ with extracellular $\mathrm{Na}^{+}$at 1:1 ratio. When the intracellular $\mathrm{Na}^{+}$concentration is elevated, as in the presence of upregulated $\mathrm{INa}_{\mathrm{p}}$, NCX acts as a symport, allowing inflow of both $\mathrm{Na}^{+}$and $\mathrm{Ca}^{2+}$. This process, besides directly elevating intracellular $\mathrm{Ca}^{2+}$, determines membrane depolarization thus promoting further ER- and $\mathrm{Ca}_{\mathrm{v}}$-mediated $\mathrm{Ca}^{2+}$ entry with a feed-forward mechanism. The rise in intracellular $\mathrm{Ca}^{2+}$ levels is then thought to cause activate multiple cell death cascades ([100] [101,102],).

Compelling preclinical evidence that elevated neuronal excitability and excitotoxicity are major determinants of ALS has prompted attempts to develop neuroprotective treatments based on this rationale. In fact, the only drug currently approved for ALS which shows some disease-modifying efficacy is riluzole, which is supposed to exert its neuroprotective activity by inhibiting $\mathrm{Na}_{\mathrm{V}} 1.6$ channels and excessive glutamate release. Collectively, data collected from randomized controlled trials suggest that riluzole typically extends survival by 2-3 months, increasing by $\sim 9 \%$ the chance of an additional year of survival [103], indicating a significant, yet modest, neuroprotective efficacy. Based on a similar rationale, the $\mathrm{Na}_{\mathrm{V}}$ blocker and antiarrhythmic flecainide was tested in a phase II clinical study. Due to the short duration of the study (32 weeks) and relatively small sample (54 patients), the study was not designed to detect evidence of disease-modifying properties, although flecainide groups showed significant improvement in axonal conduction properties [104].

The evidence that pharmacological manipulation of a disease-specific IM has, although unsatisfactory, disease-modifying capacity in clinical ALS, should encourage further exploration of this class of targets with basic and preclinical studies. Fig. 2 (middle) schematizes major ALS-related alteration in IMs and in the electrical activity of the affected neuron.

\section{Spinocerebellar ataxia}

Spinocerebellar ataxias (SCAs) are an aetiologically heterogeneous group of movement disorders characterized by a relatively homogeneous set of clinical manifestations including alterations in gait, eye and limb movement, and speech. A common pathological denominator of SCAs is the involvement of Cerebellar Purkinje neurons (PNs), although other cerebellar and brainstem neurons may be affected [105]. Although the severity of symptoms and degree of disability may vary to a large extent, SCA is a progressive and irreversible disease often leading to death, as no effective neuroprotective or symptomatic treatments are available. In spite of the clinical similarities, the aetiology of SCAs displays a great degree of diversity. In contrast with the majority of NDDs, most SCAs have a known genetic cause. Over forty mutations have been discovered to cause SCA with autosomal dominant, autosomal recessive, or X-linked mechanism of inheritance [105]. This number keeps growing as new SCA causing mutations are described [106]. As mentioned, PNs are typically most affected, and IMs participate to neuropathology in a dual manner: 1) as primary diseasecausing factors when expressed in mutated forms; 2) as downstream disease mechanisms activated by causing factors of other nature.

PNs are extremely large GABAergic neurons, with extensive dendritic arborisation, whose tonic, sustained AP firing $(\sim 40 \mathrm{~Hz})$ constitutes the main output of the cerebellar cortex. Synaptic modulation of tonic firing activity and GABA release on projection motor nuclei of the brainstem is at the basis of the primary function of the cerebellum, i.e., the coordination of motor functions. The AP cycle in these neurons is initiated by a subthreshold depolarization phase sustained by $\mathrm{Na}_{\mathrm{V}}$ 1.6. When the potential approaches firing threshold, $\mathrm{Na}_{\mathrm{V}} 1.1$ activate and drive the AP upstroke. The next repolarization phase relies mainly on the activation of $\mathrm{K}_{\mathrm{V}} 3.3$ channels. $\mathrm{Ca}_{\mathrm{V}} 2.1$ and 3 are also activated during the AP. The resulting $\mathrm{Ca}^{2+}$ entry, in turn, activates $\mathrm{BK}$ and SK channels mediating the after-hyperpolarization (AHP). AHP permits complete de-inactivation of $\mathrm{Na}_{\mathrm{V}} 1.6$ which are now ready to start a new AP cycle. Mutations in any of the ion channels governing this complex process may disrupt AP cycle, normal $\mathrm{Ca}^{2+}$ homeostasis and, in some cases, promote neuronal death. Mutations in the KCND3 gene, coding for $K_{V}$ 4.3, cause SCA 19/22 [107]. These mutations result in reduced surface expression and current density of the channel. Interestingly, since the expression of $\mathrm{K}_{\mathrm{V}} 4.3$ has not been clearly demonstrated in PNs, the reason why these degenerate is still unclear. The presence of $K_{V} 4.3$ in granule cells and molecular layer interneurons, two cerebellar neuronal populations making direct synaptic contacts with PNs, suggests the contribution of non-cell autonomous mechanisms, such as disruption of the excitation/inhibition balance and excitotoxicity [108]. Transient receptor potential channel type 3 (TRPC3) is a $\mathrm{Ca}^{2+}$-permeable, non-selective channel expressed in PNs, where it is essential for the induction of Long-Term Depression in these neurons [109]. In humans, mutations in TRPC3 cause SCA41, in some cases associated to neurodegeneration [110]. Consistently, a dominant gain-of-function mutation (T635A) in TRPC3 causes motor impairment and progressive PN degeneration in the moonwalker mice. In these mice, PN firing is abnormally prone to depolarization block, suggesting that TRPC3 may also be involved in the normal AP generation cycle [111].

In humans, mutations in the itpr1 gene, encoding the type 1 Inositol 1,4,5-trisphosphate receptor $\left(\mathrm{IP}_{3} \mathrm{R} 1\right.$ ), are responsible for SCA15/16 and SCA 29, two forms with very distinct clinical profile, with the former characterized by adult-onset, slow-progressing ataxia and atrophy, the latter by congenital-onset, non-progressive ataxia with additional cerebellar dysfunctions [112]. The $\mathrm{IP}_{3} \mathrm{R}$ is a $\mathrm{Ca}^{2+}$ channel gated by $\mathrm{IP}_{3}$ and expressed on the ER membrane. Engagement of $\mathrm{IP}_{3}$ signalling in PNs is largely, although not solely, a consequence of type 1 metabotropic glutamate receptor activation by excitatory afferents onto PNs [112]. Multiple studies have provided converging evidence that SCA15/16 is caused by $\mathrm{IP}_{3} \mathrm{R} 1$ haploinsufficiency [113] and mice carrying spontaneous as well as engineered itpr 1 mutations leading to reduced $\mathrm{IP}_{3} \mathrm{R} 1$ protein levels display neurological alterations consistent with the human disease [114,115].

Poly glutamine (poly-Q) mutations account for the vast majority of SCA cases. They consist in a variable expansion of the glutamine-encoding CAG repeat in the gene coding sequence. Among SCA-causing mutations, SCA1, 2, 3, 6, 7 and 17 are caused by poly-Q-affected gene. In SCA6, the poly-Q-expansion directly affects an IM encoding gene (CACNA1A), which codes for the pore-forming subunit $\mathrm{CaV} 2.1$. Homozygous SCA6 [84Q] mice show alteration of PN electrical activity, which is partially restored by administration of 4-aminopyridine, $\mathrm{K}_{\mathrm{V}}$ blocker, $\mathrm{K}_{\mathrm{Ca}}$ enhancer [116]. There is no evidence of neuropathology in this strain [117], suggesting that SCA6 is a pure channelopathy. In the remaining poly-Q SCAs, mutated genes are involved in transcriptional regulation (ATXN1, ATXN7, TBP), RNA metabolism (ATXN2), protein turnover and degradation (ATXN3). Mouse models of poly-Q SCAs have revealed that downstream alterations in gene expression pattern and molecular pathways are largely overlapping across mutations, and many of the secondarily dysregulated pathways involve key IMs $[105,118]$. SCA1 is caused by ATXN1 [82Q] mutation. ATXN1 is regulator of RNA transcription, and poly-Q expansion leads to transcriptional and functional downregulation of BK and G-protein inward rectifying $\mathrm{K}^{+}$channels (GIRK; [119]). In transgenic mice carrying the pathogenic mutation, PNs display depolarized membrane potential and reduced AHP amplitude. In combination, these alterations lead to 
depolarization block due to the inability of $\mathrm{Na}_{\mathrm{V}} 1.6$ to fully de-inactivate at the end of the descending phase of the AP. Dendritic atrophy has been demonstrated during disease progression, a process that has been interpreted as a homeostatic response able to partially restore BK and GIRK current density, membrane potential value, AHP amplitude and intrinsic AP firing [119]. In a mouse model of SCA2, associated to the ATXN2 [127Q] mutation, transcriptional downregulation of $\mathrm{BK}$ and $\mathrm{K}_{\mathrm{V}}$ 3.3 channels is associated, early in disease progression, to disruption of PN electrical activity. As in SCA1, near-normal PN spiking is restored by compensatory IMs of uncertain nature. Nevertheless, later stages are characterized by clear PN loss [120]. In ATXN2 [58Q], the mutated protein interacts with the $\mathrm{COOH}$ terminal of the $\mathrm{IP}_{3} \mathrm{R} 1$, thus increasing its sensitivity to $\mathrm{IP}_{3}$ and facilitating $\mathrm{ER} \mathrm{Ca}{ }^{2+}$ release. Interestingly, PN degeneration and ataxia symptoms were alleviated by administration of dantrolene in mice expressing the ATXN2 [58Q] mutation [121] The ATXN3 [84Q] mutation is at the basis of SCA3, the most common SCA with autosomal dominant inheritance. In this form, motor impairment results, in the early phase, from alteration in PN firing. Later on, PN degeneration occurs in a number of cases [122]. PN degeneration seems to correlate with disrupted regulation of $\mathrm{Ca}^{2+}$ release from intracellular stores, as ATXN3 interacts with the $\mathrm{Ca}^{2+}$ release machinery.

Collectively, results from studies on the numerous IMs-associated forms of SCA indicate that defective ionic activity, via neuronal hyperexcitability and $\mathrm{Ca}^{2+}$ dishomeostasis, can promote both clinical manifestations and neuropathology, including neuronal death. Arguably, normalizing dysfunctional IMs would provide dual benefit. SCA mutations are heterogenerous in nature and daunting in number, making it extremely challenging targeting each of them for neuroprotection. However, studies on the most frequent forms (SCA1, 2, 3 and 6) highlight the involvement of a relatively small number of dysfunctional IMs across multiple aetiologies, such as $\mathrm{K}_{\mathrm{Ca}}$ channels, and aberrant $\mathrm{Ca}^{2+}$ release from intracellular stores. Fig. 2 (bottom) illustrates the link between disruption of IMs and electrical activity with neuronal death in SCA.

Based on the massive evidence of a causal role for the derangement of intracellular $\mathrm{Ca}^{2+}$ handling in SCA, a number of attempt to target these mechanisms have been made, albeit only at preclinical stage. Pharmacological control of $\mathrm{Ca}^{2+}$ release from intracellular stores with the RyR blocker dantrolene ameliorates motor performance and PN degeneration in animal models of SCA 2 and 3 [121,123]. Similar results were obtained with viral-mediated overexpression of the $\mathrm{IP}_{3}$ phosphatase 5 P P in SCA2 mice [124].

In many SCA forms, neuronal degeneration arises as a consequence of a deleterious electrical phenotype, rather than as a direct consequence of the altered IM. As there is generally some degree of redundancy in the IMs controlling the electrical properties of neurons, any pharmacological intervention able to normalize such aberrant phenotype, although not directly targeting the defective IM, may in principle afford neuroprotective efficacy. Based on this line of reasoning, one laboratory has tested compounds able to normalize $\mathrm{K}^{+}$ currents in animal models of the disease. Chlorzoxazone, a $\mathrm{K}_{\mathrm{Ca}}$ channels activator, and baclofen, a $\mathrm{GABA}_{\mathrm{B}}$ receptor agonist, proved able to cooperatively exert a partial rescue of the normal electrophysiological phenotype of PNs in brain slices from ATXN1 [82Q] mice, and oral coadministration ameliorated ataxia symptoms [125]. Interestingly, the same work reports a retrospective study on patients with different SCA forms, treated with chlorzoxazone and/or baclofen as a symptomatic therapy. Results indicate that chlorzoxazone + baclofen coadministration is well tolerated and that it provides some moderate improvement in standard neurological tests.

Finally, the ALS drug riluzole is currently being tested in a phase IIb/III, randomized, double-blind, placebo-controlled clinical study (NCT02960893). The rationale of the latter study is the demonstrated ability of riluzole to enhance activated $\mathrm{K}_{\mathrm{Ca}}$ currents [105]. Although preliminary, these results are promising and encourage additional efforts aimed at testing the neuroprotective potential of additional IMs modulators in preclinical models and extending the comprehension of common ionic bases underlying distinct SCA forms.

\section{Degenerative retinal disorders}

Several diseases affecting the retina and leading to blindness are associated to degeneration of retinal cells. These diseases will be collectively referred to as degenerative retinal disorders (DRDs). In some DRDs, the degenerating structure is the retinal pigment epithelium (RPE), a basal layer of cells with trophic function. Some DRDs are caused by mutations in organ-specific IMs. Mutations in the BEST1 gene cause a subtype of DRDs, normally referred to as "bestrophinopathies". Over 200 BEST1 mutations have been discovered leading to the five known bestrophinopathies. BEST1 codes for the Bestrophin 1 protein, the single unit of a pentameric $\mathrm{Ca}^{2+}$-dependent anionic channel which localizes to the basal membrane of RPE cells [126]. In addition to functioning as an anion channel, Best1 also serves as a regulator of intracellular $\mathrm{Ca}^{2+}$ signalling and homeostasis. [144,145].

Cyclic Nucleotide Gated (CNG) channels are key elements of the phototransduction machinery in photoreceptors. The CNG family is composed, in mammals, by six members, CNGA1-4, CNGB1 and CNGB3. CNG channels are expressed in the outer segment of photoreceptors and mediate the so called "dark current", a mixed, non-inactivating $\mathrm{Na}^{+} / \mathrm{Ca}^{2+}$ current, resulting in a depolarized $(\sim-40 \mathrm{mV})$ potential and a tonic release of glutamate vesicles from the basal membrane. Light stimulation leads to closure of CNG channels, membrane hyperpolarization $(\sim-65 \mathrm{mV})$ and glutamate release cessation. Several mutations in CNGA1 and CNGB1 genes have been associated to RP. It is believed that $1-8 \%$ of retinitis pigmentosa (RP) cases are accounted by mutations in these two genes [127]. CNGB1 KO mice show early functional defect, followed by pathological sings of human RP, including compromised rod-mediated vision and rod degeneration, which later extend to cones [128]. Functional studies performed on RPcausing CNGB1 mutations have uncovered a set of heterogeneous defects ranging from functional inactivation to impaired channel targeting or stability [129]. Therefore, it is unclear whether CNGB1-related RP depends on disrupted ionic activity. Regardless of the nature of the pathogenic pathways triggered by mutated CNG channels, there is considerable ongoing effort in the development of Adeno-Associated Virus (AAV)-mediated gene therapies for RP cure. Following the path opened by Luxturna $^{\odot}$, a recently approved cure for RPE65-associated retinal dystrophy [130], preclinical studies are testing the efficacy of AAV-based gene supplementation therapy for CNGB1-linked RP45 [131].

\section{Conclusion and perspectives}

Neuroprotection is the main unmet medical need in the management of NDDs. Incomplete understanding of the underlying pathogenic mechanisms explains, at least in part, the substantial failure in the development of disease-modifying approaches [23]. Indeed, preclinical and genetic studies have uncovered an unexpected level of complexity and diversity in the molecular pathways implicated within individual NDDs [132]. It is now increasingly recognized that classical NDD definitions, mainly based on neurological assessment, neuroimaging and post-mortem neuropathological evaluation, are inadequate to reveal the multifaceted nature of each pathology. In the future, effective genetic profiling will likely reshape classical definitions and, hopefully, guide targeted therapy. On the diagnostic side, provided that reliable biomarkers and instrumental methods for earlier diagnosis are available, affected individuals will be genetically profiled and diagnosed with a specific NDD molecular subtype, ideally before symptoms onset, in time for state-of-the-art therapy. On the therapeutic side, however, unravelling all the mechanistic complexity of a given NDD implies that physicians will have to face multiple diseases instead of one. The task appears overly challenging also for pharmacologists in their effort to 


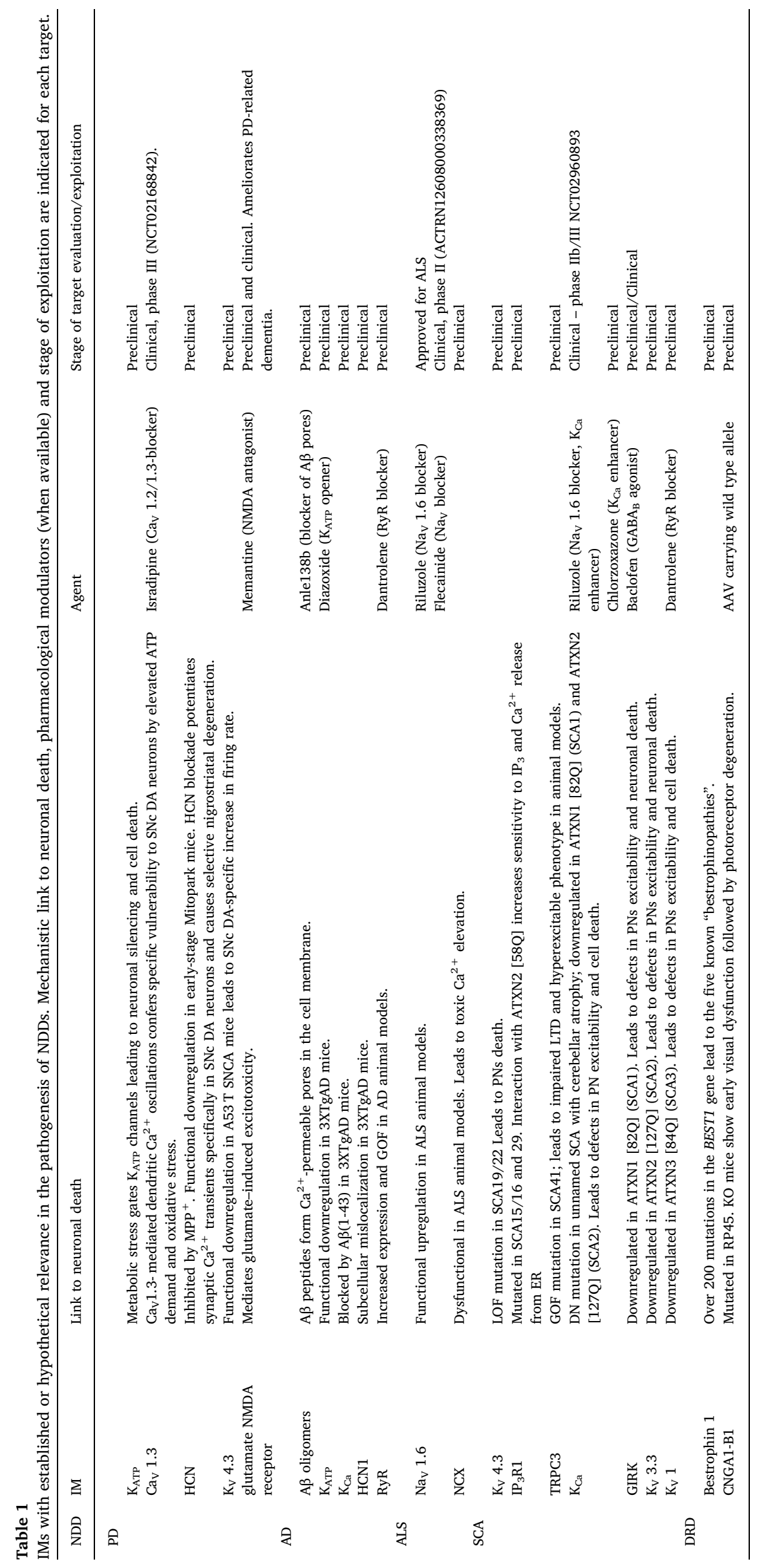


develop tools with disease-modifying capability, as the number of pathways with pathogenic relevance in NDDs is constantly rising. On the one hand, extending our molecular understanding of NDDs, especially in sporadic forms, is of paramount importance to unravel new specific targets. On the other hand, exploiting targets with relevance across pathways may simplify and expedite the development of effective compounds. In this regard, compelling evidence suggests that the number of NDD-associated dysfunctional IMs is quite limited as compared to the complexity of upstream pathways. In addition, certain electrophysiological alterations have been associated to neurodegeneration in distinct NDDs, suggesting that pharmacological correction of a given pathological electrical phenotype may have neuroprotective efficacy in multiple pathologies [133-136].

Evidence for a strong causal link between IMs and neuronal death is compelling for many NDDs (Table 1). Dissection of the electrophysiological alterations characterizing NDDs at cellular level, largely provided by excellent functional studies in animal models, clearly points to the existence of electrical phenotypes promoting cellular pathology. Depending on the NDD class and the disease pathway recapitulated in the animal model, electrical phenotype promoting vulnerability may be innate or acquired. In PD models, both normal electrical properties $\left(\mathrm{Ca}_{\mathrm{V}} 1\right.$.3-mediated dendritic $\mathrm{Ca}^{2+}$ activity) or acquired alterations (i.e. aberrant firing rate, increased synaptic excitability) resulting from the activation of specific disease pathways ( $\alpha$ synuclein signalling, UPS inhibition, metabolic stress) have been implied in the selective vulnerability of midbrain dopaminergic neurons $[38,39,53,137]$. In particular, $\mathrm{Ca}^{2+}$ activity is emerging as a pathogenic component with broad relevance in PD forms with multiple aetiologies $[41,43,46]$. In terms of therapeutic perspectives, the pharmacological correction of the "risky" electrical phenotype appears amenable, as shown by the case of isradipine, a dihydropyridine targeting $\mathrm{Ca}_{\mathrm{V}} 1.2$ and 1.3, previously approved for the treatment of high blood pressure and now undergoing a re-purposing process whose rationale is provided by the comprehension of the electrical determinants of dopaminergic vulnerability in PD $[138,139]$. If successful, the isradipine study will not only provide the first available disease-modifying pharmacological tool in PD, but also pave the way for the exploration of other IMs as neuroprotective targets.

Dysregulated $\mathrm{Ca}^{2+}$ handling has also been extensively linked to the pathogenesis of AD $[69,140]$. However, observational studies on cohorts of subjects taking $\mathrm{Ca}^{2+}$ antagonists for cardiovascular diseases have provided controversial results [141]. An alternate strategy is targeting ER $\mathrm{Ca}^{2+}$ channels, such as the RyR and $\mathrm{IP}_{3} \mathrm{R}$ [142]. Indeed, modulating $\mathrm{ER} \mathrm{Ca}^{2+}$ with the RyR blocker and ER stabilizer dantrolene has proven effective in animal models [70]. The translation of dantrolene to the clinical setting is however limited by the poor brain penetrance, which warrants future chemical reformulation of the compound.

Certain risky electrophysiological profiles are shared by distinct NDDs. As a consequence, drugs correcting such profiles may provide cross-disease neuroprotective efficacy. The concept of the cross-disease relevance of IMs is well exemplified by ALS and SCA. In both disorders, aberrant neuronal excitability and excitotoxicity have been proposed as powerful drivers of neurodegeneration [89,105]. The existence of a similar hyperexcitable profile in ALS and SCA [96,108] provides a strong rationale for the protective action of riluzole, a $\mathrm{Na}_{\mathrm{V}}$ blocker reducing excessive spiking. Although the protective efficacy of riluzole is limited in ALS and still under clinical evaluation in SCA, the example highlights the potential of an approach targeting electrical alterations, especially when these have similar relevance in multiple disorders.

In all areas of pharmacology, a major obstacle that must be overcome when exploring new targets is the possible lack of target specificity. IMs involved in neurodegenerative processes are not, with few exceptions, expressed exclusively in the neuronal populations at risk or as a result of NDD-specific pathogenic cascades. In fact, most of the IMs discussed in the present review are broadly expressed within and even outside the CNS. Raising the lipophilicity of promising molecules may help the achievement of effective concentrations in the nervous tissue avoiding dose-limiting peripheral side effects. An even greater challenge is posed by the need to limit off-target effects within the CNS. The issue of selectivity may be overcome by engineering drugs with better target specificity on one side, or by identifying new targets with stronger disease specificity on the other side. In this respect, some degree of selectivity may be afforded by the fact that target mechanisms are often aberrantly functional in the involved population and thus possibly more sensitive to the effects of a modulation in the opposite direction.

In conclusion, it is our opinion that pharmacological research should intensify its effort on the exploration of IMs as targets for neuroprotectants in diseases where preclinical studies point to the existence of a pathogenic electrical component. The paradigmatic case of isradipine highlights another important potential advantage of harnessing IMs, i.e. the opportunity to feed fast-track repositioning programs by gleaning from the enormous armamentarium of available, safe compounds acting on this target category.

\section{Acknowledgements}

The authors have received funding from Regione Toscana (Bando in Materia di Salute 2009, AM), The Michael J Fox Foundation for Parkinson's Research (Rapid Response Innovation Award 2011, AM, GM), Ministero della Salute, (Bando Ricerca Finalizzata e Giovani Ricercatori 2011-2012, AM) and Fondazione Ente Cassa di Risparmio di Firenze (GM).

\section{References}

[1] C.M. Lill, Genetics of Parkinson's disease, Mol. Cell. Probes 30 (2016) 386-396.

[2] T. Klockgether, C. Mariotti, H.L. Paulson, Spinocerebellar ataxia, Nat. Rev. Dis. Primers 5 (2019) 24.

[3] B.W. Kunkle, B. Grenier-Boley, R. Sims, J.C. Bis, V. Damotte, A.C. Naj, A. Boland, M. Vronskaya, S.J. van der Lee, A. Amlie-Wolf, C. Bellenguez, A. Frizatti, V. Chouraki, E.R. Martin, K. Sleegers, N. Badarinarayan, J. Jakobsdottir, K.L. Hamilton-Nelson, S. Moreno-Grau, R. Olaso, R. Raybould, Y. Chen, A.B. Kuzma, M. Hiltunen, T. Morgan, S. Ahmad, B.N. Vardarajan, J. Epelbaum, P. Hoffmann, M. Boada, G.W. Beecham, J.G. Garnier, D. Harold, A.L. Fitzpatrick, O. Valladares, M.L. Moutet, A. Gerrish, A.V. Smith, L. Qu, D. Bacq, N. Denning, X. Jian, Y. Zhao, M. Del Zompo, N.C. Fox, S.H. Choi, I. Mateo, J.T. Hughes, H.H. Adams, J. Malamon, F. Sanchez-Garcia, Y. Patel, J.A. Brody, B.A. Dombroski, M.C.D. Naranjo, M. Daniilidou, G. Eiriksdottir, S. Mukherjee, D. Wallon, J. Uphill, T. Aspelund, L.B. Cantwell, F. Garzia, D. Galimberti, E. Hofer, M. Butkiewicz, B. Fin, E. Scarpini, C. Sarnowski, W.S. Bush, S. Meslage, J. Kornhuber, C.C. White, Y. Song, R.C. Barber, S. Engelborghs, S. Sordon, D. Voijnovic, P.M. Adams, R. Vandenberghe, M. Mayhaus, L.A. Cupples, M.S. Albert, P.P. De Deyn, W. Gu, J.J. Himali, D. Beekly, A. Squassina, A.M. Hartmann, A. Orellana, D. Blacker, E. Rodriguez-Rodriguez, S. Lovestone, M.E. Garcia, R.S. Doody, C. MunozFernadez, R. Sussams, H. Lin, T.J. Fairchild, Y.A. Benito, C. Holmes, H. KaramujicComic, M.P. Frosch, H. Thonberg, W. Maier, G. Roschupkin, B. Ghetti, V. Giedraitis, A. Kawalia, S. Li, R.M. Huebinger, L. Kilander, S. Moebus, I. Hernandez, M.I. Kamboh, R. Brundin, J. Turton, Q. Yang, M.J. Katz, L. Concari, J. Lord, A.S. Beiser, C.D. Keene, S. Helisalmi, I. Kloszewska, W.A. Kukull, A.M. Koivisto, A. Lynch, L. Tarraga, E.B. Larson, A. Haapasalo, B. Lawlor, T.H. Mosley, R.B. Lipton, V. Solfrizzi, M. Gill, W.T. Longstreth Jr., T.J. Montine, V. Frisardi, M. Diez-Fairen, F. Rivadeneira, R.C. Petersen, V. Deramecourt, I. Alvarez, F. Salani, A. Ciaramella, E. Boerwinkle, E.M. Reiman, N. Fievet, J.I. Rotter, J.S. Reisch, O. Hanon, C. Cupidi, A.G. Andre Uitterlinden, D.R. Royall, C. Dufouil, R.G. Maletta, I. de Rojas, M. Sano, A. Brice, R. Cecchetti, P.S. GeorgeHyslop, K. Ritchie, M. Tsolaki, D.W. Tsuang, B. Dubois, D. Craig, C.K. Wu, H. Soininen, D. Avramidou, R.L. Albin, L. Fratiglioni, A. Germanou, L.G. Apostolova, L. Keller, M. Koutroumani, S.E. Arnold, F. Panza, O. Gkatzima, S. Asthana, D. Hannequin, P. Whitehead, C.S. Atwood, P. Caffarra, H. Hampel, I. Quintela, A. Carracedo, L. Lannfelt, D.C. Rubinsztein, L.L. Barnes, F. Pasquier, L. Frolich, S. Barral, B. McGuinness, T.G. Beach, J.A. Johnston, J.T. Becker, P. Passmore, E.H. Bigio, J.M. Schott, T.D. Bird, J.D. Warren, B.F. Boeve, M.K. Lupton, J.D. Bowen, P. Proitsi, A. Boxer, J.F. Powell, J.R. Burke, J.S.K. Kauwe, J.M. Burns, M. Mancuso, J.D. Buxbaum, U. Bonuccelli, N.J. Cairns, A. McQuillin, C. Cao, G. Livingston, C.S. Carlson, N.J. Bass, C.M. Carlsson, J. Hardy, R.M. Carney, J. Bras, M.M. Carrasquillo, R. Guerreiro, M. Allen, H.C. Chui, E. Fisher, C. Masullo, E.A. Crocco, C. DeCarli, G. Bisceglio, M. Dick, L. Ma, R. Duara, N.R. Graff-Radford, D.A. Evans, A. Hodges, K.M. Faber, M. Scherer, K.B. Fallon, M. Riemenschneider, D.W. Fardo, R. Heun, M.R. Farlow, H. Kolsch, S. Ferris, M. Leber, T.M. Foroud, I. Heuser, D.R. Galasko, I. Giegling, 
M. Gearing, M. Hull, D.H. Geschwind, J.R. Gilbert, J. Morris, R.C. Green, K. Mayo, J.H. Growdon, T. Feulner, R.L. Hamilton, L.E. Harrell, D. Drichel, L.S. Honig, T.D. Cushion, M.J. Huentelman, P. Hollingworth, C.M. Hulette, B.T. Hyman, R. Marshall, G.P. Jarvik, A. Meggy, E. Abner, G.E. Menzies, L.W. Jin, G. Leonenko, L.M. Real, G.R. Jun, C.T. Baldwin, D. Grozeva, A. Karydas, G. Russo, J.A. Kaye, R. Kim, F. Jessen, N.W. Kowall, B. Vellas, J.H. Kramer, E. Vardy, F.M. LaFerla, K.H. Jockel, J.J. Lah, M. Dichgans, J.B. Leverenz, D. Mann, A.I. Levey, S. Pickering-Brown, A.P. Lieberman, N. Klopp, K.L. Lunetta, H.E. Wichmann, C.G. Lyketsos, K. Morgan, D.C. Marson, K. Brown, F. Martiniuk, C. Medway, D.C. Mash, M.M. Nothen, E. Masliah, N.M. Hooper, W.C. McCormick, A. Daniele, S.M. McCurry, A. Bayer, A.N. McDavid, J. Gallacher, A.C. McKee, H. van den Bussche, M. Mesulam, C. Brayne, B.L. Miller, S. Riedel-Heller, C.A. Miller, J.W. Miller, A. Al-Chalabi, J.C. Morris, C.E. Shaw, A.J. Myers, J. Wiltfang, S. O’Bryant, J.M. Olichney, V. Alvarez, J.E. Parisi, A.B. Singleton, H.L. Paulson, J. Collinge, W.R. Perry, S. Mead, E. Peskind, D.H. Cribbs, M. Rossor, A. Pierce, N.S. Ryan, W.W. Poon, B. Nacmias, H. Potter, S. Sorbi, J.F. Quinn, E. Sacchinelli, A. Raj, G. Spalletta, M. Raskind, C. Caltagirone, P. Bossu, M.D. Orfei, B. Reisberg, R. Clarke, C. Reitz, A.D. Smith, J.M. Ringman, D. Warden, E.D. Roberson, G. Wilcock, E. Rogaeva, A.C. Bruni, H.J. Rosen, M. Gallo, R.N. Rosenberg, Y. BenShlomo, M.A. Sager, P. Mecocci, A.J. Saykin, P. Pastor, M.L. Cuccaro, J.M. Vance, J.A. Schneider, L.S. Schneider, S. Slifer, W.W. Seeley, A.G. Smith, J.A. Sonnen, S. Spina, R.A. Stern, R.H. Swerdlow, M. Tang, R.E. Tanzi, J.Q. Trojanowski, J.C. Troncoso, V.M. Van Deerlin, L.J. Van Eldik, H.V. Vinters, J.P. Vonsattel, S. Weintraub, K.A. Welsh-Bohmer, K.C. Wilhelmsen, J. Williamson, T.S. Wingo, R.L. Woltjer, C.B. Wright, C.E. Yu, L. Yu, Y. Saba, A. Pilotto, M.J. Bullido, O. Peters, P.K. Crane, D. Bennett, P. Bosco, E. Coto, V. Boccardi, P.L. De Jager, A. Lleo, N. Warner, O.L. Lopez, M. Ingelsson, P. Deloukas, C. Cruchaga, C. Graff, R. Gwilliam, M. Fornage, A.M. Goate, P. Sanchez-Juan, P.G. Kehoe, N. Amin, N. Ertekin-Taner, C. Berr, S. Debette, S. Love, L.J. Launer, S.G. Younkin, J.F. Dartigues, C. Corcoran, M.A. Ikram, D.W. Dickson, G. Nicolas, D. Campion, J. Tschanz, H. Schmidt, H. Hakonarson, J. Clarimon, R. Munger, R. Schmidt, L.A. Farrer, C. Van Broeckhoven, M, C.O.D, A.L. DeStefano, L. Jones, J.L. Haines, J.F. Deleuze, M.J. Owen, V. Gudnason, R. Mayeux, V. Escott-Price, B.M. Psaty, A. Ramirez, L.S. Wang, A. Ruiz, C.M. van Duijn, P.A. Holmans, S. Seshadri, J. Williams, P. Amouyel, G.D. Schellenberg, J.C. Lambert, M.A. Pericak-Vance, Genetic meta-analysis of diagnosed Alzheimer's disease identifies new risk loci and implicates Abeta, tau, immunity and lipid processing, Nat. Genet. 51 (2019) 414-430.

[4] M.T. Lo, K. Kauppi, C.C. Fan, N. Sanyal, E.T. Reas, V.S. Sundar, W.C. Lee, R.S. Desikan, L.K. McEvoy, C.H. Chen, Identification of genetic heterogeneity of Alzheimer's disease across age, Neurobiol. Aging (2019).

[5] D. Nolan, J. Fink, Genetics of epilepsy, Handb. Clin. Neurol. 148 (2018) 467-491.

[6] J.S. Farrell, M.D. Wolff, G.C. Teskey, Neurodegeneration and pathology in epilepsy: clinical and basic perspectives, Adv. Neurobiol. 15 (2017) 317-334.

[7] X.Y. Tai, B. Bernhardt, M. Thom, P. Thompson, S. Baxendale, M. Koepp, N. Bernasconi, Review: neurodegenerative processes in temporal lobe epilepsy with hippocampal sclerosis: clinical, pathological and neuroimaging evidence, Neuropathol. Appl. Neurobiol. 44 (2018) 70-90.

[8] B. Liss, A. Neu, J. Roeper, The weaver mouse gain-of-function phenotype of dopaminergic midbrain neurons is determined by coactivation of wvGirk2 and KATP channels, J. Neurosci. 19 (1999) 8839-8848.

[9] M.E. Raichle, D.A. Gusnard, Appraising the brain's energy budget, Proc Natl Acad Sci U S A 99 (2002) 10237-10239.

[10] D.J. Surmeier, P.T. Schumacker, Calcium, bioenergetics, and neuronal vulnerability in Parkinson's disease, J. Biol. Chem. 288 (2013) 10736-10741.

[11] M.J. Berridge, M.D. Bootman, H.L. Roderick, Calcium signalling: dynamics, homeostasis and remodelling, Nat. Rev. Mol. Cell Biol. 4 (2003) 517-529.

[12] C. Giorgi, S. Marchi, P. Pinton, The machineries, regulation and cellular functions of mitochondrial calcium, Nat. Rev. Mol. Cell Biol. 19 (2018) 713-730.

[13] P.S. Brookes, Y. Yoon, J.L. Robotham, M.W. Anders, S.S. Sheu, Calcium, ATP, and ROS: a mitochondrial love-hate triangle, Am. J. Physiol., Cell Physiol. 287 (2004) C817-833.

[14] S. Gandhi, A. Wood-Kaczmar, Z. Yao, H. Plun-Favreau, E. Deas, K. Klupsch, J. Downward, D.S. Latchman, S.J. Tabrizi, N.W. Wood, M.R. Duchen, A.Y. Abramov, PINK1-associated Parkinson's disease is caused by neuronal vulnerability to calcium-induced cell death, Mol. Cell 33 (2009) 627-638.

[15] K.W. Kinnally, P.M. Peixoto, S.Y. Ryu, L.M. Dejean, Is mPTP the gatekeeper for necrosis, apoptosis, or both? Biochim. Biophys. Acta 1813 (2011) 616-622.

[16] D. Westphal, G. Dewson, P.E. Czabotar, R.M. Kluck, Molecular biology of Bax and Bak activation and action, Biochim. Biophys. Acta 1813 (2011) 521-531.

[17] A. Gorlach, K. Bertram, S. Hudecova, O. Krizanova, Calcium and ROS: a mutual interplay, Redox Biol. 6 (2015) 260-271.

[18] P.K. Stys, Q. Jiang, Calpain-dependent neurofilament breakdown in anoxic and ischemic rat central axons, Neurosci. Lett. 328 (2002) 150-154.

[19] S.A. Susin, H.K. Lorenzo, N. Zamzami, I. Marzo, B.E. Snow, G.M. Brothers, J. Mangion, E. Jacotot, P. Costantini, M. Loeffler, N. Larochette, D.R. Goodlett, R. Aebersold, D.P. Siderovski, J.M. Penninger, G. Kroemer, Molecular character ization of mitochondrial apoptosis-inducing factor, Nature 397 (1999) 441-446.

[20] L.M. de Lau, M.M. Breteler, Epidemiology of Parkinson's disease, Lancet Neurol. 5 (2006) 525-535.

[21] K. Nuytemans, J. Theuns, M. Cruts, C. Van Broeckhoven, Genetic etiology of Parkinson disease associated with mutations in the SNCA, PARK2, PINK1, PARK7, and LRRK2 genes: a mutation update, Hum. Mutat. 31 (2010) 763-780.

[22] A. Verstraeten, J. Theuns, C. Van Broeckhoven, Progress in unraveling the genetic etiology of Parkinson disease in a genomic era, Trends Genet. 31 (2015) 140-149.

[23] A.E. Lang, A.J. Espay, Disease Modification in Parkinson's Disease: Current
Approaches, Challenges, and Future Considerations, Mov. Disord. 33 (2018) 660-677.

[24] A.H. Schapira, Aetiopathogenesis of Parkinson's disease, J. Neurol. 258 (2011) S307-310.

[25] L. Brichta, P. Greengard, Molecular determinants of selective dopaminergic vulnerability in Parkinson's disease: an update, Front. Neuroanat. 8 (2014) 152.

[26] F. Roselli, P. Caroni, From intrinsic firing properties to selective neuronal vulnerability in neurodegenerative diseases, Neuron 85 (2015) 901-910.

[27] A.A. Grace, B.S. Bunney, Intracellular and extracellular electrophysiology of nigral dopaminergic neurons-2. Action potential generating mechanisms and morphological correlates, Neuroscience 10 (1983) 317-331.

[28] D.J. Surmeier, J.N. Mercer, C.S. Chan, Autonomous pacemakers in the basal ganglia: who needs excitatory synapses anyway? Curr. Opin. Neurobiol. 15 (2005) 312-318.

[29] G.H. Kim, J.E. Kim, S.J. Rhie, S. Yoon, The role of oxidative stress in neurodegenerative diseases, Exp. Neurobiol. 24 (2015) 325-340.

[30] E. Dragicevic, J. Schiemann, B. Liss, Dopamine midbrain neurons in health and Parkinson's disease: emerging roles of voltage-gated calcium channels and ATPsensitive potassium channels, Neuroscience 284 (2015) 798-814.

[31] B. Liss, J. Roeper, ATP-sensitive potassium channels in dopaminergic neurons: transducers of mitochondrial dysfunction, News Physiol. Sci. 16 (2001) 214-217.

[32] C.G. Nichols, KATP channels as molecular sensors of cellular metabolism, Nature 440 (2006) 470-476.

[33] B. Liss, O. Haeckel, J. Wildmann, T. Miki, S. Seino, J. Roeper, K-ATP channels promote the differential degeneration of dopaminergic midbrain neurons, Nat. Neurosci. 8 (2005) 1742-1751.

[34] J. Duda, C. Pötschke, B. Liss, Converging roles of ion channels, calcium, metabolic stress, and activity pattern of Substantia nigra dopaminergic neurons in health and Parkinson's disease, J. Neurochem. (2016) 156-178.

[35] P.S. Freestone, K.K. Chung, E. Guatteo, N.B. Mercuri, L.F. Nicholson, J. Lipski, Acute action of rotenone on nigral dopaminergic neurons-involvement of reactive oxygen species and disruption of Ca2 + homeostasis, Eur. J. Neurosci. 30 (2009) 1849-1859.

[36] M. Giustizieri, M.L. Cucchiaroni, E. Guatteo, G. Bernardi, N.B. Mercuri, $\mathrm{N}$. Berretta, Memantine inhibits ATP-dependent $\mathrm{K}+$ conductances in dopamine neurons of the rat substantia nigra pars compacta, J. Pharmacol. Exp. Ther. 322 (2007) 721-729.

[37] H. Piri, H. Haghdoost-Yazdi, N. Fraidouni, T. Dargahi, M. Yaghoubidoust, A. Azadmehr, The anti-parkinsonism effects of KATP channel blockade in the 6Hydroxydopamine-Induced animal model: the role of oxidative stress, Basic Clin. Neurosci. 8 (2017) 183-192.

[38] M. Subramaniam, B. Kern, S. Vogel, V. Klose, G. Schneider, J. Roeper, Selective increase of in vivo firing frequencies in DA SN neurons after proteasome inhibition in the ventral midbrain, Eur. J. Neurosci. 40 (2014) 2898-2909.

[39] M. Subramaniam, D. Althof, S. Gispert, J. Schwenk, G. Auburger, A. Kulik, B. Fakler, J. Roeper, Mutant $\alpha$-synuclein enhances firing frequencies in dopamine substantia nigra neurons by oxidative impairment of A-type potassium channels, $\mathrm{J}$. Neurosci. 34 (2014) 13586-13599.

[40] C.S. Chan, J.N. Guzman, E. Ilijic, J.N. Mercer, C. Rick, T. Tkatch, G.E. Meredith, D.J. Surmeier, 'ReJuvenation' protects neurons in mouse models of Parkinson's disease, Nature 447 (2007) 1081-1086.

[41] J.N. Guzman, J. Sanchez-Padilla, D. Wokosin, J. Kondapalli, E. Ilijic, P.T. Schumacker, D.J. Surmeier, Oxidant stress evoked by pacemaking in dopaminergic neurons is attenuated by DJ-1, Nature 468 (2010) 696-700.

[42] J.N. Guzman, E. Ilijic, B. Yang, J. Sanchez-Padilla, D. Wokosin, D. Galtieri, J. Kondapalli, P.T. Schumacker, D.J. Surmeier, Systemic isradipine treatment diminishes calcium-dependent mitochondrial oxidant stress, J. Clin. Invest. 128 (2018) 2266-2280.

[43] D.I. Dryanovski, J.N. Guzman, Z. Xie, D.J. Galteri, L.A. Volpicelli-Daley, V.M. Lee, R.J. Miller, P.T. Schumacker, D.J. Surmeier, Calcium entry and $\alpha$-synuclein inclusions elevate dendritic mitochondrial oxidant stress in dopaminergic neurons, J. Neurosci. 33 (2013) 10154-10164.

[44] E. Ilijic, J.N. Guzman, D.J. Surmeier, The L-type channel antagonist isradipine is neuroprotective in a mouse model of Parkinson's disease, Neurobiol. Dis. 43 (2011) 364-371.

[45] D.J. Surmeier, G.M. Halliday, T. Simuni, Calcium, mitochondrial dysfunction and slowing the progression of Parkinson's disease, Exp. Neurol. 298 (2017) 202-209.

[46] B. Ritz, S.L. Rhodes, L. Qian, E. Schernhammer, J.H. Olsen, S. Friis, L-type calcium channel blockers and Parkinson disease in Denmark, Ann. Neurol. 67 (2010) 600-606.

[47] K.C. Simon, X. Gao, H. Chen, M.A. Schwarzschild, A. Ascherio, Calcium channel blocker use and risk of Parkinson's disease, Mov. Disord. 25 (2010) 1818-1822.

[48] A. Masi, R. Narducci, E. Landucci, F. Moroni, G. Mannaioni, MPP(+) -dependent inhibition of Ih reduces spontaneous activity and enhances EPSP summation in nigral dopamine neurons, Br. J. Pharmacol. 169 (2013) 130-142.

[49] N.B. Mercuri, A. Bonci, P. Calabresi, A. Stefani, G. Bernardi, Properties of the hyperpolarization-activated cation current Ih in rat midbrain dopaminergic neurons, Eur. J. Neurosci. 7 (1995) 462-469.

[50] G. Zolles, N. Klöcker, D. Wenzel, J. Weisser-Thomas, B.K. Fleischmann, J. Roeper, B. Fakler, Pacemaking by HCN channels requires interaction with phosphoinositides, Neuron 52 (2006) 1027-1036.

[51] H. Neuhoff, A. Neu, B. Liss, J. Roeper, I(h) channels contribute to the different functional properties of identified dopaminergic subpopulations in the midbrain, J. Neurosci. 22 (2002) 1290-1302.

[52] A. Masi, R. Narducci, F. Resta, C. Carbone, K. Kobayashi, G. Mannaioni, Differential contribution of Ih to the integration of excitatory synaptic inputs in 
substantia nigra pars compacta and ventral tegmental area dopaminergic neurons, Eur. J. Neurosci. 42 (2015) 2699-2706.

[53] C. Carbone, A. Costa, G. Provensi, G. Mannaioni, A. Masi, The hyperpolarizationactivated current determines synaptic excitability, calcium activity and specific viability of substantia nigra dopaminergic neurons, Front. Cell. Neurosci. 11 (2017) 187.

[54] C.H. Good, A.F. Hoffman, B.J. Hoffer, V.I. Chefer, T.S. Shippenberg, C.M. Bäckman, N.G. Larsson, L. Olson, S. Gellhaar, D. Galter, C.R. Lupica, Impaired nigrostriatal function precedes behavioral deficits in a genetic mitochondrial model of Parkinson's disease, FASEB J. 25 (2011) 1333-1344.

[55] S.Y. Branch, C. Chen, R. Sharma, J.D. Lechleiter, S. Li, M.J. Beckstead, Dopaminergic neurons exhibit an age-dependent decline in electrophysiological parameters in the MitoPark mouse model of parkinson's disease, J. Neurosci. 36 (2016) 4026-4037.

[56] M. Novella Romanelli, L. Sartiani, A. Masi, G. Mannaioni, D. Manetti, A. Mugelli, E. Cerbai, HCN channels modulators: the need for selectivity, Curr. Top. Med. Chem. 16 (2016) 1764-1791.

[57] A.K. Friedman, J.J. Walsh, B. Juarez, S.M. Ku, D. Chaudhury, J. Wang, X. Li, D.M. Dietz, N. Pan, V.F. Vialou, R.L. Neve, Z. Yue, M.H. Han, Enhancing depression mechanisms in midbrain dopamine neurons achieves homeostatic resilience, Science 344 (2014) 313-319.

[58] E. Lagrue, S. Chalon, S. Bodard, E. Saliba, P. Gressens, P. Castelnau, Lamotrigine is neuroprotective in the energy deficiency model of MPTP intoxicated mice, Pediatr. Res. 62 (2007) 14-19.

[59] S. Mittal, K. Bjornevik, D.S. Im, A. Flierl, X. Dong, J.J. Locascio, K.M. Abo, E. Long, M. Jin, B. Xu, Y.K. Xiang, J.C. Rochet, A. Engeland, P. Rizzu, P. Heutink, T. Bartels, D.J. Selkoe, B.J. Caldarone, M.A. Glicksman, V. Khurana, B. Schule, D.S. Park, T. Riise, C.R. Scherzer, beta2-Adrenoreceptor is a regulator of the alpha-synuclein gene driving risk of Parkinson's disease, Science 357 (2017) 891-898.

[60] L. Brennan, A. Pantelyat, J.E. Duda, J.F. Morley, D. Weintraub, J.R. Wilkinson, P.J. Moberg, Memantine and cognition in parkinson's disease Dementia/Dementia with Lewy Bodies: a meta-analysis, Mov. Disord. Clin. Pract. 3 (2016) 161-167.

[61] M. Merello, M.I. Nouzeilles, A. Cammarota, R. Leiguarda, Effect of memantine (NMDA antagonist) on Parkinson's disease: a double-blind crossover randomized study, Clin. Neuropharmacol. 22 (1999) 273-276.

[62] P.S. Verhave, M.J. Jongsma, R.M. Van Den Berg, R.A. Vanwersch, A.B. Smit, I.H. Philippens, Neuroprotective effects of riluzole in early phase Parkinson's disease on clinically relevant parameters in the marmoset MPTP model, Neuropharmacology 62 (2012) 1700-1707.

[63] J. Jankovic, C. Hunter, A double-blind, placebo-controlled and longitudinal study of riluzole in early Parkinson's disease, Parkinsonism Relat. Disord. 8 (2002) $271-276$.

[64] D.J. Selkoe, The molecular pathology of Alzheimer's disease, Neuron 6 (1991) 487-498.

[65] D.P. Perl, Neuropathology of Alzheimer's disease, Mt. Sinai J. Med. 77 (2010) $32-42$

[66] C. Reitz, R. Mayeux, Alzheimer disease: epidemiology, diagnostic criteria, risk factors and biomarkers, Biochem. Pharmacol. 88 (2014) 640-651.

[67] B. Nacmias, S. Bagnoli, I. Piaceri, S. Sorbi, Genetic Heterogeneity of Alzheimer's Disease: Embracing Research Partnerships, J. Alzheimers Dis. 62 (2018) 903-911.

68] M.P. Mattson, Calcium and neurodegeneration, Aging Cell 6 (2007) 337-350.

[69] I. Bezprozvanny, M.P. Mattson, Neuronal calcium mishandling and the pathogenesis of Alzheimer's disease, Trends Neurosci. 31 (2008) 454-463.

[70] S. Chakroborty, G.E. Stutzmann, Calcium channelopathies and Alzheimer's disease: insight into therapeutic success and failures, Eur. J. Pharmacol. 739 (2014) 83-95.

[71] H.B. Pollard, E. Rojas, N. Arispe, A new hypothesis for the mechanism of amyloid toxicity, based on the calcium channel activity of amyloid beta protein (A beta P) in phospholipid bilayer membranes, Ann. N. Y. Acad. Sci. 695 (1993) 165-168.

[72] M. Kawahara, N. Arispe, Y. Kuroda, E. Rojas, Alzheimer's disease amyloid betaprotein forms $\mathrm{Zn}(2+)$-sensitive, cation-selective channels across excised membrane patches from hypothalamic neurons, Biophys. J. 73 (1997) 67-75.

[73] A. Demuro, E. Mina, R. Kayed, S.C. Milton, I. Parker, C.G. Glabe, Calcium dysre gulation and membrane disruption as a ubiquitous neurotoxic mechanism of soluble amyloid oligomers, J. Biol. Chem. 280 (2005) 17294-17300.

[74] D.C. Bode, M.D. Baker, J.H. Viles, Ion channel formation by Amyloid-beta42 oligomers but not Amyloid-beta40 in cellular membranes, J. Biol. Chem. 292 (2017) 1404-1413.

[75] L.V. Colom, M.E. Diaz, D.R. Beers, A. Neely, W.J. Xie, S.H. Appel, Role of potassium channels in amyloid-induced cell death, J. Neurochem. 70 (1998) 1925-1934.

[76] T.A. Good, D.O. Smith, R.M. Murphy, Beta-amyloid peptide blocks the fast-inactivating $\mathrm{K}+$ current in rat hippocampal neurons, Biophys. J. 70 (1996) 296-304.

[77] R.J. Mark, K. Hensley, D.A. Butterfield, M.P. Mattson, Amyloid beta-peptide impairs ion-motive ATPase activities: evidence for a role in loss of neuronal Ca2+ homeostasis and cell death, J. Neurosci. 15 (1995) 6239-6249.

[78] S. Oddo, A. Caccamo, J.D. Shepherd, M.P. Murphy, T.E. Golde, R. Kayed, R. Metherate, M.P. Mattson, Y. Akbari, F.M. LaFerla, Triple-transgenic model of Alzheimer's disease with plaques and tangles: intracellular Abeta and synaptic dysfunction, Neuron 39 (2003) 409-421.

[79] D. Liu, M. Pitta, J.H. Lee, B. Ray, D.K. Lahiri, K. Furukawa, M. Mughal, H. Jiang, J. Villarreal, R.G. Cutler, N.H. Greig, M.P. Mattson, The KATP channel activator diazoxide ameliorates amyloid-beta and tau pathologies and improves memory in the 3xTgAD mouse model of Alzheimer's disease, J. Alzheimers Dis. 22 (2010) 443-457.
[80] K. Yamamoto, Y. Ueta, L. Wang, R. Yamamoto, N. Inoue, K. Inokuchi, A. Aiba, H. Yonekura, N. Kato, Suppression of a neocortical potassium channel activity by intracellular amyloid-beta and its rescue with Homer1a, J. Neurosci. 31 (2011) $11100-11109$

[81] A. Martinez Hernandez, H. Urbanke, A.L. Gillman, J. Lee, S. Ryazanov, H.Y. Agbemenyah, E. Benito, G. Jain, L. Kaurani, G. Grigorian, A. Leonov, N. Rezaei-Ghaleh, P. Wilken, F.T. Arce, J. Wagner, M. Fuhrmann, M. Caruana, A. Camilleri, N. Vassallo, M. Zweckstetter, R. Benz, A. Giese, A. Schneider, M. Korte, R. Lal, C. Griesinger, G. Eichele, A. Fischer, The diphenylpyrazole compound anle138b blocks Abeta channels and rescues disease phenotypes in a mouse model for amyloid pathology, EMBO Mol. Med. 10 (2018) 32-47.

[82] J. Wagner, S. Ryazanov, A. Leonov, J. Levin, S. Shi, F. Schmidt, C. Prix, F. PanMontojo, U. Bertsch, G. Mitteregger-Kretzschmar, M. Geissen, M. Eiden, F. Leidel, T. Hirschberger, A.A. Deeg, J.J. Krauth, W. Zinth, P. Tavan, J. Pilger, M. Zweckstetter, T. Frank, M. Bahr, J.H. Weishaupt, M. Uhr, H. Urlaub, U. Teichmann, M. Samwer, K. Botzel, M. Groschup, H. Kretzschmar, C. Griesinger, A. Giese, Anle138b: a novel oligomer modulator for disease-modifying therapy of neurodegenerative diseases such as prion and Parkinson's disease, Acta Neuropathol. 125 (2013) 795-813.

[83] A. Heras-Garvin, D. Weckbecker, S. Ryazanov, A. Leonov, C. Griesinger, A. Giese, G.K. Wenning, N. Stefanova, Anle138b modulates alpha-synuclein oligomerization and prevents motor decline and neurodegeneration in a mouse model of multiple system atrophy, Mov. Disord. 34 (2019) 255-263.

[84] G.E. Stutzmann, I. Smith, A. Caccamo, S. Oddo, F.M. Laferla, I. Parker, Enhanced ryanodine receptor recruitment contributes to $\mathrm{Ca} 2+$ disruptions in young, adult, and aged Alzheimer's disease mice, J. Neurosci. 26 (2006) 5180-5189.

[85] S. Chakroborty, C. Briggs, M.B. Miller, I. Goussakov, C. Schneider, J. Kim, J. Wicks, J.C. Richardson, V. Conklin, B.G. Cameransi, G.E. Stutzmann, Stabilizing $\mathrm{ER} \mathrm{Ca2}+$ channel function as an early preventative strategy for Alzheimer's disease, PLoS One 7 (2012) e52056.

[86] T.F. Musial, E. Molina-Campos, L.A. Bean, N. Ybarra, R. Borenstein, M.L. Russo, E.W. Buss, D. Justus, K.M. Neuman, G.D. Ayala, S.A. Mullen, Y. Voskobiynyk, C.T. Tulisiak, J.A. Fels, N.J. Corbett, G. Carballo, C.D. Kennedy, J. Popovic, J. Ramos-Franco, M. Fill, M.R. Pergande, J.A. Borgia, G.T. Corbett, K. Pahan, Y. Han, D.M. Chetkovich, R.J. Vassar, R.W. Byrne, M. Matthew Oh, T.R. Stoub, S. Remy, J.F. Disterhoft, D.A. Nicholson, Store depletion-induced h-channel plasticity rescues a channelopathy linked to Alzheimer's disease, Neurobiol. Learn. Mem. 154 (2018) 141-157.

[87] R. Knight, M. Khondoker, N. Magill, R. Stewart, S. Landau, A systematic review and meta-analysis of the effectiveness of acetylcholinesterase inhibitors and memantine in treating the cognitive symptoms of dementia, Dement. Geriatr. Cogn. Disord. 45 (2018) 131-151.

[88] R. Wang, P.H. Reddy, Role of Glutamate and NMDA Receptors in Alzheimer's Disease, J. Alzheimers Dis. 57 (2017) 1041-1048.

[89] P. Menon, M.C. Kiernan, S. Vucic, Biomarkers and future targets for development in amyotrophic lateral sclerosis, Curr. Med. Chem. 21 (2014) 3535-3550.

[90] O. Pansarasa, M. Bordoni, L. Diamanti, D. Sproviero, S. Gagliardi, C. Cereda, SOD1 in amyotrophic lateral sclerosis: "Ambivalent" behavior connected to the disease, Int. J. Mol. Sci. 19 (2018)

[91] M.E. Gurney, H. Pu, A.Y. Chiu, M.C. Dal Canto, C.Y. Polchow, D.D. Alexander, J. Caliendo, A. Hentati, Y.W. Kwon, H.X. Deng, et al., Motor neuron degeneration in mice that express a human $\mathrm{Cu}, \mathrm{Zn}$ superoxide dismutase mutation, Science 264 (1994) 1772-1775.

[92] A.G. Reaume, J.L. Elliott, E.K. Hoffman, N.W. Kowall, R.J. Ferrante, D.F. Siwek, H.M. Wilcox, D.G. Flood, M.F. Beal, R.H. Brown Jr., R.W. Scott, W.D. Snider, Motor neurons in $\mathrm{Cu} / \mathrm{Zn}$ superoxide dismutase-deficient mice develop normally but exhibit enhanced cell death after axonal injury, Nat. Genet. 13 (1996) 43-47.

[93] J.P. Taylor, R.H. Brown, D.W. Cleveland, Decoding ALS: from genes to mechanism, Nature 539 (2016) 197-206.

[94] M.R. Turner, O. Hardiman, M. Benatar, B.R. Brooks, A. Chio, M. de Carvalho, P.G. Ince, C. Lin, R.G. Miller, H. Mitsumoto, G. Nicholson, J. Ravits, P.J. Shaw, M. Swash, K. Talbot, B.J. Traynor, L.H.V. den Berg, J.H. Veldink, S. Vucic, M.C. Kiernan, Controversies and priorities in amyotrophic lateral sclerosis, Lancet Neurol. 12 (2013) 310-322.

[95] S. Vucic, M.C. Kiernan, Pathophysiology of neurodegeneration in familial amyotrophic lateral sclerosis, Curr. Mol. Med. 9 (2009) 255-272.

[96] S.B. Park, M.C. Kiernan, S. Vucic, Axonal Excitability in Amyotrophic Latera Sclerosis : Axonal Excitability in ALS, Neurotherapeutics 14 (2017) 78-90.

[97] J.J. Kuo, T. Siddique, R. Fu, C.J. Heckman, Increased persistent $\mathrm{Na}$ (+) current an its effect on excitability in motoneurones cultured from mutant SOD1 mice, J. Physiol. (Paris) 563 (2005) 843-854.

[98] M. Pieri, I. Carunchio, L. Curcio, N.B. Mercuri, C. Zona, Increased persistent sodium current determines cortical hyperexcitability in a genetic model of amyotrophic lateral sclerosis, Exp. Neurol. 215 (2009) 368-379.

[99] S. Vucic, M.C. Kiernan, Upregulation of persistent sodium conductances in familia ALS, J Neurol Neurosurg Psychiatry 81 (2010) 222-227.

[100] P.K. Stys, S.G. Waxman, B.R. Ransom, Na(+)-Ca2 + exchanger mediates Ca2 + influx during anoxia in mammalian central nervous system white matter, Ann. Neurol. 30 (1991) 375-380.

[101] P.K. Stys, S.G. Waxman, B.R. Ransom, Ionic mechanisms of anoxic injury in mammalian CNS white matter: role of $\mathrm{Na}+$ channels and $\mathrm{Na}(+)-\mathrm{Ca} 2+\mathrm{ex}-$ changer, J. Neurosci. 12 (1992) 430-439.

[102] U. Wojda, E. Salinska, J. Kuznicki, Calcium ions in neuronal degeneration, IUBMB Life 60 (2008) 575-590.

[103] M. Hinchcliffe, A. Smith, Riluzole: real-world evidence supports significant extension of median survival times in patients with amyotrophic lateral sclerosis, 
Degener. Neurol. Neuromuscul. Dis. 7 (2017) 61-70.

[104] S.B. Park, S. Vucic, B.C. Cheah, C.S. Lin, A. Kirby, K.P. Mann, M.C. Zoing, J. Winhammar, M.C. Kiernan, Flecainide in amyotrophic lateral sclerosis as a neuroprotective strategy (FANS): a randomized placebo-controlled trial, EBioMedicine 2 (2015) 1916-1922.

[105] D.D. Bushart, V.G. Shakkottai, Ion channel dysfunction in cerebellar ataxia, Neurosci. Lett. (2018).

[106] B.W. Soong, P.J. Morrison, Spinocerebellar ataxias, Handb. Clin. Neurol. 155 (2018) 143-174.

[107] A. Duarri, M.C. Lin, M.R. Fokkens, M. Meijer, C.J. Smeets, E.A. Nibbeling, E. Boddeke, R.J. Sinke, H.H. Kampinga, D.M. Papazian, D.S. Verbeek, Spinocerebellar ataxia type 19/22 mutations alter heterocomplex Kv4.3 channel function and gating in a dominant manner, Cell. Mol. Life Sci. 72 (2015) 3387-3399.

[108] Y.H. Hsu, H.Y. Huang, M.L. Tsaur, Contrasting expression of Kv4.3, an A-type K+ channel, in migrating Purkinje cells and other post-migratory cerebellar neurons, Eur. J. Neurosci. 18 (2003) 601-612.

[109] S.J. Kim, TRPC3 channel underlies cerebellar long-term depression, Cerebellum 12 (2013) 334-337.

[110] B.L. Fogel, S.M. Hanson, E.B. Becker, Do mutations in the murine ataxia gene TRPC3 cause cerebellar ataxia in humans? Mov. Disord. 30 (2015) 284-286.

[111] G. Sekerkova, J.A. Kim, M.J. Nigro, E.B. Becker, J. Hartmann, L. Birnbaumer, E. Mugnaini, M. Martina, Early onset of ataxia in moonwalker mice is accompanied by complete ablation of type II unipolar brush cells and Purkinje cell dysfunction, J. Neurosci. 33 (2013) 19689-19694.

[112] C. Hisatsune, K. Hamada, K. Mikoshiba, $\mathrm{Ca}(2+)$ signaling and spinocerebellar ataxia, Biochim Biophys Acta Mol Cell Res 1865 (2018) 1733-1744.

[113] M. Synofzik, C. Beetz, C. Bauer, M. Bonin, E. Sanchez-Ferrero, T. Schmitz-Hubsch, U. Wullner, T. Nagele, O. Riess, L. Schols, P. Bauer, Spinocerebellar ataxia type 15: diagnostic assessment, frequency, and phenotypic features, J. Med. Genet. 48 (2011) 407-412.

[114] M. Matsumoto, T. Nakagawa, T. Inoue, E. Nagata, K. Tanaka, H. Takano, O. Minowa, J. Kuno, S. Sakakibara, M. Yamada, H. Yoneshima, A. Miyawaki, Y. Fukuuchi, T. Furuichi, H. Okano, K. Mikoshiba, T. Noda, Ataxia and epileptic seizures in mice lacking type 1 inositol 1,4,5-trisphosphate receptor, Nature 379 (1996) 168-171.

[115] V.A. Street, M.M. Bosma, V.P. Demas, M.R. Regan, D.D. Lin, L.C. Robinson, W.S. Agnew, B.L. Tempel, The type 1 inositol 1,4,5-trisphosphate receptor gene is altered in the opisthotonos mouse, J. Neurosci. 17 (1997) 635-645.

[116] S. Jayabal, H.H. Chang, K.E. Cullen, A.J. Watt, 4-aminopyridine reverses ataxia and cerebellar firing deficiency in a mouse model of spinocerebellar ataxia type 6, Sci. Rep. 6 (2016) 29489

[117] K. Watase, C.F. Barrett, T. Miyazaki, T. Ishiguro, K. Ishikawa, Y. Hu, T. Unno, Y. Sun, S. Kasai, M. Watanabe, C.M. Gomez, H. Mizusawa, R.W. Tsien, H.Y. Zoghbi, Spinocerebellar ataxia type 6 knockin mice develop a progressive neuronal dysfunction with age-dependent accumulation of mutant CaV2.1 channels, Proc Natl Acad Sci U S A (2008) 11987-11992.

[118] C. Bettencourt, M. Ryten, P. Forabosco, S. Schorge, J. Hersheson, J. Hardy, H. Houlden, Insights from cerebellar transcriptomic analysis into the pathogenesis of ataxia, JAMA Neurol. 71 (2014) 831-839.

[119] J.M. Dell'Orco, A.H. Wasserman, R. Chopra, M.A. Ingram, Y.S. Hu, V. Singh, H. Wulff, P. Opal, H.T. Orr, V.G. Shakkottai, Neuronal atrophy early in degenerative Ataxia Is a compensatory mechanism to regulate membrane excitability, $\mathrm{J}$. Neurosci. 35 (2015) 11292-11307.

[120] S.T. Hansen, P. Meera, T.S. Otis, S.M. Pulst, Changes in Purkinje cell firing and gene expression precede behavioral pathology in a mouse model of SCA2, Hum. Mol. Genet. 22 (2013) 271-283.

[121] J. Liu, T.S. Tang, H. Tu, O. Nelson, E. Herndon, D.P. Huynh, S.M. Pulst, I. Bezprozvanny, Deranged calcium signaling and neurodegeneration in spinocerebellar ataxia type 2, J. Neurosci. 29 (2009) 9148-9162.

[122] L. Schols, P. Bauer, T. Schmidt, T. Schulte, O. Riess, Autosomal dominant cerebellar ataxias: clinical features, genetics, and pathogenesis, Lancet Neurol. 3 (2004) 291-304.

[123] X. Chen, T.S. Tang, H. Tu, O. Nelson, M. Pook, R. Hammer, N. Nukina, I. Bezprozvanny, Deranged calcium signaling and neurodegeneration in spinocerebellar ataxia type 3, J. Neurosci. 28 (2008) 12713-12724.

[124] A.W. Kasumu, X. Liang, P. Egorova, D. Vorontsova, I. Bezprozvanny, Chronic suppression of inositol 1,4,5-triphosphate receptor-mediated calcium signaling in cerebellar purkinje cells alleviates pathological phenotype in spinocerebellar ataxia 2 mice, J. Neurosci. 32 (2012) 12786-12796.

[125] D.D. Bushart, R. Chopra, V. Singh, G.G. Murphy, H. Wulff, V.G. Shakkottai, Targeting potassium channels to treat cerebellar ataxia, Ann. Clin. Transl. Neurol. 5 (2018) 297-314.

[126] A.A. Johnson, K.E. Guziewicz, C.J. Lee, R.C. Kalathur, J.S. Pulido, L.Y. Marmorstein, A.D. Marmorstein, Bestrophin 1 and retinal disease, Prog. Retin. Eye Res. 58 (2017) 45-69.

[127] D.T. Hartong, E.L. Berson, T.P. Dryja, Retinitis pigmentosa, Lancet 368 (2006) 1795-1809.

[128] S. Huttl, S. Michalakis, M. Seeliger, D.G. Luo, N. Acar, H. Geiger, K. Hudl, R. Mader, S. Haverkamp, M. Moser, A. Pfeifer, A. Gerstner, K.W. Yau, M. Biel, Impaired channel targeting and retinal degeneration in mice lacking the cyclic nucleotide-gated channel subunit CNGB1, J. Neurosci. 25 (2005) 130-138.

[129] S. Michalakis, E. Becirovic, M. Biel, Retinal cyclic nucleotide-gated channels: from pathophysiology to therapy, Int. J. Mol. Sci. 19 (2018).

[130] A. Lloyd, N. Piglowska, T. Ciulla, S. Pitluck, S. Johnson, M. Buessing, T. O'Connell, Estimation of impact of RPE65-mediated inherited retinal disease on quality of life and the potential benefits of gene therapy, Br. J. Ophthalmol. (2019).

[131] S. Koch, V. Sothilingam, M. Garcia Garrido, N. Tanimoto, E. Becirovic, F. Koch, C. Seide, S.C. Beck, M.W. Seeliger, M. Biel, R. Muhlfriedel, S. Michalakis, Gene therapy restores vision and delays degeneration in the CNGB1(-/-) mouse model of retinitis pigmentosa, Hum. Mol. Genet. 21 (2012) 4486-4496.

[132] S.Y. Pang, K.C. Teo, J.S. Hsu, R.S. Chang, M. Li, P.C. Sham, S.L. Ho, The role of gene variants in the pathogenesis of neurodegenerative disorders as revealed by next generation sequencing studies: a review, Transl. Neurodegener. 6 (2017) 27.

[133] N.H. Shah, E. Aizenman, Voltage-gated potassium channels at the crossroads of neuronal function, ischemic tolerance, and neurodegeneration, Transl. Stroke Res. 5 (2014) 38-58.

[134] D. Caccamo, L.R. Pisani, P. Mazzocchetti, R. Ientile, P. Calabresi, F. Pisani, C. Costa, Neuroprotection as a potential therapeutic perspective in neurodegenerative diseases: focus on antiepileptic drugs, Neurochem. Res. 41 (2016) 340-352.

[135] I. Bezprozvanny, M.C. Sorgato, E. Carafoli, Misery loves company - shared features of neurodegenerative disorders, Biochem. Biophys. Res. Commun. 483 (2017) 979-980.

[136] M. Verma, Z. Wills, C.T. Chu, Excitatory dendritic mitochondrial calcium toxicity: implications for parkinson's and other neurodegenerative diseases, Front. Neurosci. 12 (2018) 523

[137] D.J. Surmeier, J.N. Guzman, J. Sanchez-Padilla, J.A. Goldberg, What causes the death of dopaminergic neurons in Parkinson's disease? Prog. Brain Res. 183 (2010) 59-77.

[138] T. Swart, M.J. Hurley, Calcium Channel Antagonists as Disease-Modifying Therapy for Parkinson's Disease: Therapeutic Rationale and Current Status, CNS Drugs 30 (2016) 1127-1135.

[139] B. Liss, J. Striessnig, The potential of L-Type calcium channels as a drug target for neuroprotective therapy in parkinson's disease, Annu. Rev. Pharmacol. Toxicol. 59 (2019) 263-289.

[140] M.P. Mattson, ER calcium and Alzheimer's disease: in a state of flux, Sci. Signal. 3 (2010) pe10.

[141] V. Nimmrich, A. Eckert, Calcium channel blockers and dementia, Br. J. Pharmacol 169 (2013) 1203-1210.

[142] G.E. Stutzmann, M.P. Mattson, Endoplasmic reticulum $\mathrm{Ca}(2+)$ handling in excitable cells in health and disease, Pharmacol. Rev, 63 (2011) 700-727.

[143] N. Patil, D.R. Cox, D. Bhat, M. Faham, R.M. Myers, A.S. Peterson, A potassium channel mutation in weaver mice implicates membrane excitability in granule cel differentiation, Nat. Genet. 11 (1995) 126-129.

[144] L.Y. Marmorstein, J. Wu, P. McLaughlin, J. Yocom, M.O. Karl, R. Neussert, S. Wimmers, J.B. Stanton, R.G. Gregg, O. Strauss, N.S. Peachey, A.D. Marmorstein The light peak of the electroretinogram is dependent on voltage-gated calcium channels and antagonized by bestrophin (best-1), J Gen Physiol 127 (2006) $577-589$.

[145] Y. Zhang, J.B. Stanton, J. Wu, K. Yu, H.C. Hartzell, N.S. Peachey, L.Y. Marmorstein, A.D. Marmorstein, Suppression of $\mathrm{Ca}^{2+}$ signaling in a mouse model of Best disease, Hum. Mol. Genet. 19 (2010) 1108-1118. 